\title{
DESENVOLVIMENTO DO PESSEGUEIRO EM FUNÇÃO DA INTENSIDADE DE PODA VERDE
}

\section{AlESSANDRO RODRIGUES}

\author{
Dissertação apresentada à Escola \\ Superior de Agricultura "Luiz de \\ Queiroz”, Universidade de São Paulo, \\ para obtenção do título de Mestre em \\ Agronomia, Área de Concentração: \\ Fitotecnia.
}

P I R A C I C A B A

Estado de São Paulo - Brasil

Maio - 2005 


\section{DESENVOLVIMENTO DO PESSEGUEIRO EM FUNÇÃO DA INTENSIDADE DE PODA VERDE}

\section{Alessandro Rodrigues}

Engenheiro Agrônomo

Orientador: Prof Dr. JOÃO ALEXIO SCARPARE FILHO

Dissertação apresentada à Escola
Superior de Agricultura "Luiz de
Queiroz", Universidade de São Paulo,
para obtenção do título de Mestre em
Agronomia, Área de Concentração:
Fitotecnia.

P I R A C I C A B A

Estado de São Paulo - Brasil

Maio - 2005 
Dados Internacionais de Catalogação na Publicação (CIP) DIVISÃO DE BIBLIOTECA E DOCUMENTAÇÃO - ESALQ/USP

\section{Rodrigues, Alessandro}

Desenvolvimento do pessegueiro em função da intensidade de poda verde I Alessandro Rodrigues. - - Piracicaba, 2005.

52 p. : il.

Dissertação (mestrado) - - Escola Superior de Agricultura Luiz de Queiroz, 2005.

Bibliografia.

1. Carboidratos 2. Desenvolvimento vegetal 3. Efeito da poda 4. Ferrugem (doença de planta) 5. Fruto - Qualidade 6. Pêssego I. Título

CDD 634.25

"Permitida a cópia total ou parcial deste documento, desde que citada a fonte - O autor" 
Aos meus pais AGENOR e MARA pela oportunidade concedida, pelo amor e pela confiança deposita em mim,

Aos meus irmãos KLEBER e KELLEN pelo companheirismo e incentivo,

A minha cunhada PATRÍCIA e aos meus queridos sobrinhos MAYARA, LUCAS e CAMILI,

DEDICO

“Ainda que a figueira não floresça, nem haja fruto na vide; o produto da oliveira minta, e os campos não produzam mantimento; as ovelhas sejam arrebatadas do aprisco e nos currais não haja gado, todavia eu me alegro no Senhor, exulto no Deus da minha salvação”.

Habacuque 3: 17-18

A minha amada esposa ALEXSSANDRA pelo amor, compreensão, apoio, incentivo e confiança, 


\section{AGRADECIMENTOS}

A Deus, pelo seu infinito amor.

À Universidade de São Paulo, a Escola Superior de Agricultura "Luiz de Queiroz” e ao Programa de Pós-Graduação em Fitotecnia pela oportunidade de realização do curso de Mestrado.

Ao Professor Dr. João Alexio Scarpare Filho, pela orientação, companheirismo, instrução e agradável amizade.

À CAPES pela concessão da bolsa de estudos.

Aos funcionários do Departamento de Produção Vegetal, em especial ao David, Éder e Aparecido e as secretárias Luciane, Bete e Célia.

Aos professores do curso de Pós Graduação em Fitotecnia da USP/ESALQ, em especial aos professores Ângelo Pedro Jacomino e Francisco de Assis Alves Mourão Filho.

Aos funcionários e alunos do laboratório de pós-colheita pelo auxílio.

Aos funcionários e alunos do laboratório de fitopatologia, em especial a Marise.

Ao amigo João Paulo pelo companheirismo, convivência e apoio.

Aos todos os amigos e colegas do curso pelo bom relacionamento.

Aos amigos Eduardo, Gustavo e Leonardo pela amizade e incentivo.

Aos meus sogros Florindo, Vanda e Odair pelo amparo.

A Rute pelo apoio e convivência.

Aos avós Luiz e Yolanda pelos ensinamentos passados em sua simplicidade.

A minha família 


\section{SUMÁRIO}

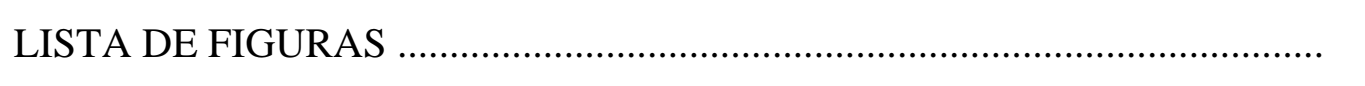

Página

LISTA DE TABELAS .................................................................................. viii

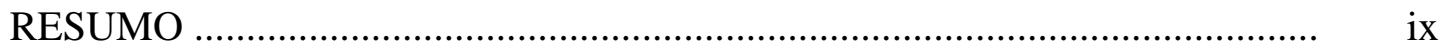

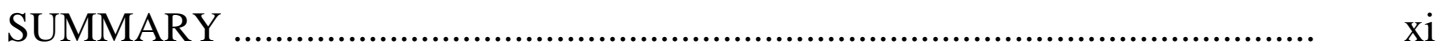

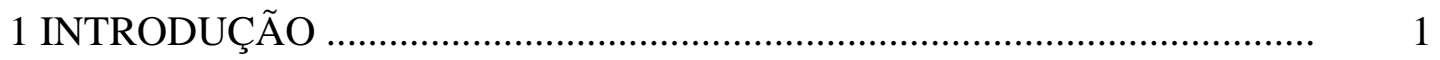

2 REVISÃO DE LITERATURA …............................................................ 3

2.1 Origem, História e Importância Econômica .................................................. 3

2.2 Classificação Botânica e Cultivares ............................................................ 5

2.3 Características do Pessegueiro .................................................................... 5

2.4 Aspectos Edafo-Climáticos .................................................................... 7

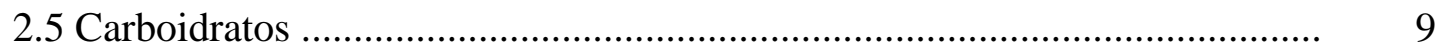

2.6 Poda em Pessegueiros............................................................................... 11

2.7 Qualidade de frutos .......................................................................... 12

2.8 Ferrugem ....................................................................................... 15

3 MATERIAL E MÉTODOS ................................................................. 18

3.1 Caracterização da Área Experimental ....................................................... 18

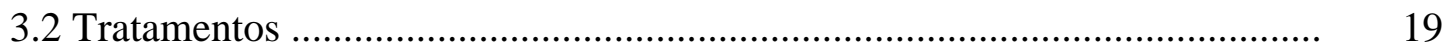

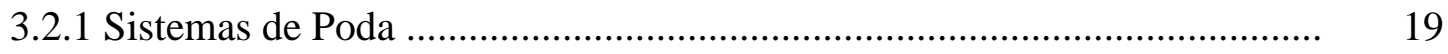

3.3 Variáveis Analisadas ........................................................................... 20

3.3.1 Florescimento Efetivo ........................................................................ 20

3.3.2 Densidade de Brotação ......................................................................... 20

3.3.3 Crescimento de Ramos ........................................................................ 21

3.3.4 Desenvolvimento de Frutos ...................................................................... 21

3.3.5 Qualidade dos Frutos .............................................................................. 22 
3.3.5.1 Massa e Tamanho dos Frutos ................................................................ 22

3.3.5.2 Coloração .................................................................................... 22

3.3.5.3 Firmeza da Polpa ........................................................................ 23

3.3.5.4 Teor de Sólidos Solúveis ( ${ }^{\mathrm{B}}$ Brix) ....................................................... 23

3.3.6 Severidade de Ferrugem ......................................................................... 23

3.3.7 Determinação das Concentrações de Carboidratos Solúveis ..................... $\quad 24$

3.4 Delineamento Experimental .................................................................... 25

3.5 Técnicas Culturais ................................................................................. 26

4 RESULTADOS E DISCUSSÃO ……………….................................. 2

4.1.Florescimento Efetivo e Densidade de Brotação Após a Poda Seca ............. 27

4.2 Crescimento de Ramos .............................................................................. 28

4.3 Desenvolvimento de Frutos ....................................................................... 29

4.4 Qualidade dos Frutos ........................................................................... $\quad 30$

4.4.1 Massa e Tamanho dos frutos ................................................................... 31

4.4.2 Coloração, Firmeza de Polpa e Teor de Sólidos Solúveis ( ${ }^{\circ}$ Brix) ............. 32

4.5 Severidade de Ferrugem ......................................................................... 32

4.6 Determinação das Concentrações de Carboidratos Solúveis ....................... 34

5 CONCLUSÕES .................................................................................... 38

REFERÊNCIAS BIBLIOGRÁFICAS ……................................................ 39

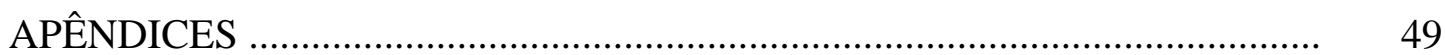




\section{LISTA DE FIGURAS}

Página

1 Área experimental em fase de dormência .................................................... 19

2 Ilustração das intensidades de poda verde utilizadas após a colheita dos

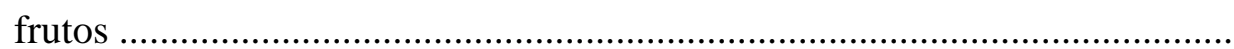

3 Início da frutificação (A) e avaliação inicial do comprimento e diâmetro de frutos (B)

4 Escala diagramática para avaliação da severidade da ferrugem (Tranzschelia discolor) em folhas

5 Retirada de solo para coleta de raízes (A) e raízes amostradas (B)

6 Crescimento de ramos de pessegueiros 'Flordaprince' em plantas submetidas à diferentes intensidades de poda verde

7 Desenvolvimento dos frutos de pessegueiros 'Flordaprince' .

8 Evolução da severidade de ferrugem (Tranzschelia discolor), em pessegueiros 'Flordaprince'

9 Sintomas de ferrugem na face superior de folhas de pessegueiro (A) e (B). 


\section{LISTA DE TABELAS}

Página

1 Características de frutos de pêssegos 'Flordaprince'

2 Qualidade dos frutos de pêssegos 'Flordaprince'

3 Severidade de ferrugem para as diferentes intensidades de poda verde estudadas em pessegueiros 'Flordaprince'

4 Concentrações de carboidratos solúveis (mg/100ml em 100\% de matéria seca), em plantas (PL) e (PD), pessegueiro 'Flordaprince'

5 Concentrações de carboidratos solúveis em raízes de plantas (PL) e (PD), em pessegueiros 'Flordaprince'

6 Concentrações de carboidratos solúveis em ramos de plantas (PL) e (PD), em pessegueiros 'Flordaprince' 


\title{
DESENVOLVIMENTO DO PESSEGUEIRO EM FUNÇÃO DA INTENSIDADE DE PODA VERDE
}

\author{
Autor: ALESSANDRO RODRIGUES \\ Orientador Prof. Dr. JOÃO ALEXIO SCARPARE FILHO
}

\section{RESUMO}

O Estado de São Paulo caracteriza-se como o principal produtor de pêssegos (Prunus persica (L.) Batsch) para consumo “in natura” do Brasil. Devido ao cultivo ser realizado em diferentes regiões e pelo uso de cultivares precoces e bem precoces, a maioria da safra ocorre na estação da primavera, antecipadamente à região Sul do Brasil. Um dos problemas decorrentes do plantio de pessegueiros em regiões mais quentes, como o Estado de São Paulo, foi o aumento considerável da ferrugem (Tranzschelia discolor). A poda verde, realizada após a colheita dos frutos, mostra-se como um dos métodos culturais utilizados pelos produtores para o manejo desta doença. O trabalho de pesquisa objetivou verificar o efeito de intensidades de poda verde após a colheita, no desenvolvimento do pessegueiro e na severidade de ferrugem. O trabalho experimental foi realizado no Campus “Luiz de Queiroz” da Universidade de São Paulo, em Piracicaba, Departamento de Produção Vegetal, sendo composto dos seguintes tratamentos: T1: poda verde de intensidade leve (PL) e T2: poda verde de intensidade drástica (PD). A área útil do ensaio foi de 345,6 m², constituída de 96 plantas conduzidas no espaçamento de 3 x 1,2 m. O delineamento experimental utilizado foi inteiramente ao acaso, constituído de 2 tratamentos e 12 repetições. As variáveis analisadas foram: florescimento efetivo; densidade de brotação; crescimento dos ramos; desenvolvimento de frutos; qualidade dos frutos (massa, tamanho, coloração, firmeza de polpa, teor de sólidos solúveis); severidade de ferrugem e determinação das concentrações de carboidratos solúveis em raízes e 
ramos em diversos períodos. De acordo com os dados obtidos pelo presente trabalho, pode-se concluir que para a cultivar Flordaprince, nas condições de Piracicaba-SP, quanto mais intensa for a poda verde realizada em outubro: menor é a concentração de carboidratos solúveis nas raízes no período de dormência; maior é o crescimento de ramos após a sua execução; menor é a fixação de frutos no próximo ciclo; menores são os teores de sólidos solúveis nos frutos. A intensidade da poda verde realizada nas mesmas condições, não interfere: na concentração de carboidratos solúveis em ramos; no florescimento efetivo, densidade de brotação e crescimento de ramos após a poda seca; no desenvolvimento, na massa, na coloração e na firmeza de frutos; na severidade de ferrugem em folhas de pessegueiro. 


\title{
DEVELOPMENT OF THE PEACH TREE RELATED TO GREEN PRUNING INTENSITY
}

\author{
Author: ALESSANDRO RODRIGUES \\ Adviser Prof. Dr. JOÃO ALEXIO SCARPARE FILHO
}

\section{SUMMARY}

Sao Paulo State has the major peach production area (Prunus persica (L.) Batsch) for fresh market in Brazil. It is characterized by early-maturing production comparing to southern states of Brazil, with harvest taking place from September to February due to the use of early-season varieties and different production areas in a warmer climate. Peach rust Tranzschelia discolor is a disease affecting peach production in Sao Paulo State and it is favored by warmer and humid conditions especially between September and April. After harvest, practices that delay peach leaf senescence are necessary because this is the period of reserve carbohydrates accumulation for next season. Drastic pruning after harvest is an important rust control method leading to new shoot sprouting and resuming vegetative growth and bud differentiation for next season. This research evaluated the effect of different intensity levels of green pruning after harvest in the development of peach trees and the rust severity. in early-maturing peach cultivar. Experimental work was carried out at "Luiz de Queiroz" campus of University of Sao Paulo, in Piracicaba, Brazil. The following treatments were used: T1 - low pruning (LP) and T2 - drastic pruning (DP), using 345,6 $\mathrm{m}^{2}$ of area with 96 plants in $3 \mathrm{~m} \mathrm{x} \mathrm{1,2} \mathrm{m} \mathrm{spacing.} \mathrm{Experimental}$ arrangement used was total randomized plots, with 2 treatments and 12 repetitions. Biometric data collected were: effective blossom, shoot density, stem length, fruit development and quality (fruit weight, diameter, color, pulp firmness and soluble solids concentration), rust severity and total soluble carbohydrate concentrations in 
roots and stems. In agreement with the data obtained by the present work, it can be ended that for to cultivate Flordaprince, in the conditions of Piracicaba-SP, the more intense it is the green pruning accomplished in october: minor is the concentration of soluble carbohydrates in the roots in the dormancy period; larger is the stem length after his execution; minor is the fixation of fruits in the next cycle; minor are the concentrations of soluble solids in the fruits. The intensity of the green pruning accomplished in the same conditions, it doesn't interfere in the concentration of soluble carbohydrates in stems; in the effective blossom; in the shoot density; in the stem lenght after the dry pruning; in the development; weight, color and the pulp firmness of fruits; in the rust severity in the peaches tree leaves. 


\section{INTRODUÇÃO}

Os plantios comerciais de pessegueiro podem ser encontrados em regiões de inverno bastante rigoroso, com 600 a 1200 horas de frio abaixo de $7,2{ }^{\circ} \mathrm{C}$, e também em regiões praticamente desprovidas de frio hibernal. No Estado de São Paulo, o cultivo econômico do pessegueiro deve-se à utilização de materiais melhorados principalmente pelo Instituto Agronômico de Campinas, no qual, a partir da década de 60, desenvolveu cultivares aclimatados às condições de inverno ameno. (Barbosa et al., 1990).

Em São Paulo, o pessegueiro é explorado desde locais de pouco frio, até nas áreas mais frescas e serranas. A produção de pêssegos no Estado caracteriza-se pela precocidade de produção em relação aos outros Estados da região Sul, fator principal do sucesso do persicultor paulista, que pode estender sua safra desde o final de agosto até dezembro. A maior parte da área plantada está instalada com cultivares precoces e bem precoces, destinadas quase que exclusivamente ao mercado de frutas “in natura”. Devido a estas características torna-se necessário desenvolver técnicas de manejo que possibilitem a melhoria da qualidade dos frutos e conseqüente aceitação por parte dos consumidores.

Um problema decorrente do plantio de pessegueiros em locais de clima mais quente, como no Estado de São Paulo, foi o aumento considerável da importância da ferrugem, causado pelo fungo Tranzschelia discolor, doença de importância esporádica em regiões temperadas. As condições climáticas favoráveis à incidência deste patógeno, aliadas à inexistência de um controle químico eficiente, tornaram essa doença, a mais preocupante em várias regiões produtoras de pêssego, onde devido à desfolha precoce, causa perdas significativas na produção. (Martins \& Amorim, 1996).

Em casos de alta severidade da doença, ocorre abscisão foliar, resultando em desfolha parcial ou quase completa da planta. (Martins \& Amorim, 1996). Isto prejudica 
os pessegueiros cultivados em regiões tropicais, pois é neste período que ocorre o acúmulo de fotoassimilados. Nas regiões subtropicais, a queda precoce das folhas pode provocar uma segunda floração no outono, com prejuízos consideráveis à planta, uma vez que essa florada não será aproveitada e a planta gasta muita energia para emiti-la, além do armazenamento de nutrientes já estar comprometido pela ausência das folhas, órgãos sintetizadores. (Bleicher \& Tanaka, 1982).

O controle químico é a medida mais usada para o controle desta doença, porém se mostra deficiente, uma vez que há pouquíssimos fungicidas registrados para a cultura. Esses produtos, além de não serem registrados para o controle da ferrugem especificamente, nem sempre fornecem controle satisfatório. (Martins, 1994).

A poda verde realizada após a colheita é uma das técnicas culturais utilizadas no controle da ferrugem. Diversos tipos de poda verde podem ser utilizados (Marini, 1985; Barbosa et al., 1999, Scarpare Filho et al., 1999.). No Estado de São Paulo, tem-se utilizado a poda de renovação (poda verde de alta intensidade ou drástica), que consiste na poda de todos os ramos da planta, que produziram ou não, realizada após a colheita de frutos. Em nossas condições, após a poda, ocorre a brotação, iniciando assim o crescimento vegetativo e a diferenciação das gemas para a safra seguinte.

O trabalho de pesquisa teve como objetivo verificar o efeito da intensidade de poda verde no desenvolvimento do pessegueiro e no controle da ferrugem. 


\section{REVISÃO DE LITERATURA}

\subsection{Origem, História e Importância Econômica}

Espécie nativa da China, o pessegueiro possui referências na literatura chinesa datadas de 20 séculos a.C. Entretanto, seu nome origina-se da Pérsia, que erroneamente é tido com seu país de origem. (Sachs \& Campos, 1998)

Provavelmente teria sido levado da China à Pérsia, onde foi cultivado e daí se espalhado pela Europa, chegando às Américas. Segundo dados da FAO (2003), a produção mundial de pêssegos e nectarinas no ano, foi da ordem de 14,7 milhões de toneladas. Os principais produtores mundiais de pêssego são a China, Estados Unidos, Itália e Espanha. Dos países da América do Sul, o Chile aparece na nona posição com uma produção de 275 mil toneladas e a Argentina empata com o Brasil na $12^{\circ}$ posição, apresentando produção em torno de 215 mil toneladas.

No Brasil, o pessegueiro foi introduzido no ano de 1532, através de mudas oriundas da Ilha da Madeira, trazidas na expedição portuguesa de Martim Afonso de Souza e plantadas em São Vicente-SP. (Simão, 1998). Originário de regiões frias, o pessegueiro entra em período de dormência e por este fato as primeiras variedades cultivadas no Brasil, foram em regiões mais frias, adaptadas, sendo que até o ano de 1950, apenas 20\% do pêssego consumido era produzido no Brasil, importando o restante sobretudo da Argentina.

O Brasil possui área superior a 20.000 hectares de cultivo de pêssegos, destinadas exclusivamente ao mercado interno. O Rio Grande do Sul apresenta-se como o principal Estado em área de cultivo, sendo que o principal destino de sua colheita aplica-se quase que exclusivamente à indústria de conservas para a produção de pêssego em calda. $\mathrm{O}$ Estado de São Paulo é o segundo maior produtor, sendo caracterizado por atender principalmente o mercado “ïn natura” (Marodin \& Sartori, 2000; Brasil, 2002.). 
O consumo de pêssegos no Brasil ainda é muito pequeno. Segundo dados da Associação Gaúcha dos Produtores de Maçã, apenas 0,85 kg por habitante/ano. Esse consumo é explicado, em grande parte, pelo reduzido poder aquisitivo da população e também pela falta de investimentos em propaganda. A produção de pêssegos no Brasil é considerada suficiente para atender à atual demanda; entretanto, com a melhoria do poder aquisitivo e com investimentos em marketing e publicidade, certamente em pouco tempo, a produção estaria muito aquém do necessário (Sachs \& Campos, 1998)

No início dos anos 50, Orlando Rigitano iniciou em São Paulo, um programa de melhoramento genético de fruteiras de clima temperado, visando obter adaptação às condições de inverno ameno, de pouca exigência em frio. (Sachs \& Campos, 1998)

O pêssego paulista amadurece naturalmente mais cedo que o produzido no Sul, e como a cultura em São Paulo é difundida em várias regiões, existe ampla época de maturação, que normalmente se estende desde setembro até fevereiro. Essa longa estação de pêssegos maduros é devida, também ao cultivo de materiais selecionados pelo Instituto Agronômico. Os principais centros produtores paulistas se localizam em Guapiara e municípios vizinhos (pêssegos tardios); Mairinque e Mogi das Cruzes (pêssegos medianos); Atibaia (pêssegos precoces-medianos) e Campinas-Valinhos (pêssegos precoces). (Ojima et al., 1984).

A conquista de novos mercados e o aumento do consumo interno são grandes desafios que se apresentam no sentido de viabilizar este importante segmento da fruticultura. A conquista de mercado está condicionada a muitos fatores, entre os quais qualidade das frutas, cultivares, período de colheita, classificação e embalagens adequadas, estruturas de frigoconservação e transporte, informações de mercado, rastreabilidade, assistência técnica, entre outros.

\subsection{Classificação Botânica e Cultivares}

O pessegueiro pertence à família Rosácea, subfamília Prunoidea, gênero Prunus (L.) e subgênero Amygdalus. Todas as cultivares comerciais pertencem à espécie Prunus persica (L.) Batsch. 
São admitidas três variedades botânicas, todas pertencentes à espécie Prunus persica (L.) Batsch: vulgaris (pêssego comum) - representa a maioria das cultivares de valor econômico para consumo "in natura” ou conserva; nucipersica - produz frutos com epiderme glabra e geralmente muito coloridas, denominadas de nectarinas, que possui esta característica devido a um fator genético recessivo e platicarpa - que produz frutos achatados da base para o ápice, característica devida a um fator genético dominante, porém raramente explorada. (Hedrick, 1916; Sachs et al., 1984).

O pessegueiro não apresenta problemas de auto-incompatibilidade, pois quase todas as variedades comerciais são autoférteis e produtivas. O problema básico reside na adaptabilidade da variedade às condições ecológicas, que variam conforme a região, razão pela qual as variedades são regionais, exigindo temperatura mínima adequada durante o período de dormência para que possam florescer e vegetar. (Ojima et al.; 1983)

A cultivar é um dos componentes mais importantes do sistema de produção e um dos poucos que podem ser modificados, sem alterar o custo de implantação do pomar. De modo geral, as cultivares de pessegueiro mais plantadas no Brasil são originárias dos programas de melhoramento genético do Instituto Agronômico de Campinas - IAC, em São Paulo, e da Embrapa Clima Temperado, em Pelotas, RS. Há, ainda, algumas criadas pela Estação Experimental de Taquari-RS, EPAGRI e IAPAR e cultivares de maturação precoce, criadas pela Universidade da Flórida, nos Estados Unidos (Raseira \& Nakasu, 1998)

\subsection{Características do Pessegueiro}

Árvore de porte médio a grande, atinge de 4 a $8 \mathrm{~m}$ de altura, sendo de pequena longevidade, iniciando a produção a partir do terceiro ano (Simão, 1998).

As raízes são a princípio pivotantes; posteriormente ramificam-se lateralmente, tornando-se numerosas, extensas e pouco profundas. A zona de exploração do sistema radicular vai muito alem da área de projeção da copa, atingindo pelo menos o dobro dessa superfície. (Sachs \& Campos, 1998) 
Os ramos são no inicio verde, passando a ter, à medida que envelhecem coloração marrom. De acordo com a distribuição de gemas de flor, eles são classificados em: mistos, que possuem comprimento variável entre 20 e $100 \mathrm{~cm}$, são portadores de gemas de flor e lenho, sendo os principais ramos produtivos; brindilas, que possuem entre 15 e 30 cm, são mais finos e mais flexíveis, predominando gemas de flor; dardos, ramos curtos de até $10 \mathrm{~cm}$ que possuem numerosas gemas floríferas e ramos ladrões que são muito vigorosos, crescem em posição vertical e possuem principalmente gemas de lenho.

As folhas, duas a quatro por nó ou gema, são do tipo completas, oblongas, lanceoladas e com pecíolos curtos. Suas dimensões são geralmente de 40-50 mm de largura por 140-180 mm de comprimento. As margens da lâmina foliar podem ser serrilhadas, crenadas ou dentadas (Sachs et al., 1984).

Em sua fase adulta, o pessegueiro caracteriza-se por sua aptidão a reprodução e pelo seu comportamento cíclico anual. A cada ano, de acordo com as características peculiares da estação climática, a planta apresenta uma fase de crescimento e outra de formação de seus órgãos reprodutivos. (Barbosa et al., 1990).

O florescimento ocorre uma única vez no ano, de junho a agosto, durante um período curto, variando de sete a vinte dias. As variedades apresentam quase sempre flores hermafroditas e autoférteis e grãos de pólen com elevada porcentagem de germinação. A quantidade de gemas floríferas apresentada por árvore varia com a idade, a variedade, o vigor, a poda e de ano para ano, sendo porém, sempre elevada. Um pessegueiro pode produzir de 15 a 40 mil flores, e a maior concentração se localiza na região intermediária do ramo da estação em desenvolvimento. (Simão, 1998).

Diversos fatores como a relação carbono/nitrogênio, podem influenciar a indução floral do pessegueiro. Quanto mais elevada for esta relação, maior será a indução floral. Nos casos em que se torna necessário diminuí-la, esperando-se excessiva frutificação para o ano seguinte, recorre-se a poda de verão. Desta forma com a eliminação de ramos e folhas, haverá uma redução na capacidade fotossintética da planta e, portanto no acúmulo de carboidratos. Adubações nitrogenadas, poda de raízes, irrigação, estado 
fitossanitário da cultura, também influem em algum sentido sobre a relação carbono/nitrogênio. (Fuertes \& Hernández, 1995).

A relação entre o volume de raízes e a parte aérea tem influência direta no período de entrada de frutificação. Nas primeiras fases (estado juvenil), o sistema radicular é relativamente grande em relação à copa que é muito reduzida. Posteriormente, se desenvolve mais a parte aérea, diminuindo esta relação, entrando em produção. Devido a este motivo, as podas realizadas nos primeiros anos devem ser leves, para que se forme a copa em menor tempo possível. (Fuertes \& Hernández, 1995).

O fruto é uma típica drupa-carnosa, com fino pericarpo, mesocarpo polposo e endocarpo lenhoso. À exceção da variedade platicarpa, o fruto apresenta forma mais ou menos esférica; podendo ser redondo, cônico, oblata, oblongo, elíptico ou ovalado. Do ponto de inserção do pedúnculo parte uma linha de sutura, que vai até o ápice do fruto. A cor da epiderme, creme-esverdeada, varia do amarelo-claro ao alaranjado e sobre essa pigmentação do fundo, muitas cultivares exibem uma rica coloração de rósea a vermelha. O pericarpo pode ser livre ou aderente à polpa. A polpa por sua vez, pode ser branca ou amarela (de amarelo-clara a alaranjada) e ser livre ou aderente ao caroço, podendo ainda apresentar pigmentação vermelha junto à epiderme e ao caroço, que em algumas cultivares cobre toda a sua extensão. (Sachs \& Campos, 1998). O sabor da polpa pode apresentar graduações na faixa doce-acidulado-forte ao simplesmente doce, com níveis de pH de 3,5 a 5,0 e de grau Brix de 8,0 a 18,0. (Barbosa et al.,1989).

\subsection{Aspectos Edafo-Climáticos}

As variedades de pêssego, nectarina, ameixa, amêndoa e abricó comercialmente cultivados nas regiões tradicionais da Europa, Estados Unidos e Japão, têm em geral, uma exigência de frio, equivalente a um total acumulado ao redor de 850 horas de temperaturas abaixo de $7,2{ }^{\circ} \mathrm{C}$, ou do que se convencionou chamar horas de frio. Esse total corresponde a um período de mais de dois meses de frio, com temperaturas médias inferiores a $10^{\circ} \mathrm{C}$. Maçãs, pêras, cerejas e nozes européias cultivadas naquelas regiões têm necessidades ainda maiores, em torno de 900 a 1000 horas de frio. Esta é a principal razão pela qual as variedades trazidas das principais áreas produtoras do mundo, e 
selecionadas para as condições de inverno que lhes são peculiares, não encontram adaptação ao clima ameno do Estado de São Paulo. (Ojima et al., 1984)

A dormência é definida como sendo “um período em que o crescimento visível é temporariamente suspenso”. Essa suspensão visível e temporária do crescimento está relacionada com estruturas das plantas que contem meristemas. (Samish, 1954; Lang et al., 1987). É um mecanismo fisiológico que as espécies caducifólias têm como meio de suportar condições adversas durante o inverno. Uma vez que a gema tenha entrado na endodormência, ela começa a requerer certa acumulação de frio para sair desta e ativarse novamente (Díaz, 1992)

Um mesmo cultivar tem uma larga faixa de resposta em termos de acúmulo de horas de temperatura abaixo de $7,2^{\circ} \mathrm{C}$, sob diferentes condições. É impossível estimar o requerimento em frio de um cultivar para todas as condições (Yarnell et al., 1939), devido às diferenças de sombreamento, da qualidade e intensidade de luz e do fotoperíodo em cada região de cultivo.

O número de horas de temperatura abaixo de $7,2^{\circ} \mathrm{C}$ vem sendo substituído no Estado de São Paulo para $13^{\circ} \mathrm{C}$, como parâmetro, pois o número de horas de frio não chega a 20, tornando-se desprezível (Pedro Junior et al., 1979).

A quebra de dormência das plantas caducifólias envolve fatores internos, como balanço dos promotores e inibidores de crescimento, ou externos, como temperatura, fotoperíodo e a radiação solar, entre outros. Dos fatores externos, o que mais se destaca é a temperatura, sendo que, quando as plantas são cultivadas em regiões com insuficiências de frio hibernal, apresentam sintomas de falta de adaptação como atraso e maior duração do período de floração e abertura de menor número de gemas floríferas e vegetativas. Isto resulta na redução da produção, gerando frutos desuniformes e de baixa qualidade (Marodin et al., 1992).

Existem técnicas para o estudo dos mecanismos envolvidos na dormência, que se fundamentam na evolução do tempo necessário para a brotação de gemas isoladas, submetidas a uma temperatura padrão, técnica chamada de estacas de nós isolada (Putti, 2001). Um método tradicional de prever a necessidade de frio das espécies e/ou cultivares consiste em submeter ramos inteiros, retirados das árvores em diferentes 
épocas, a uma temperatura favorável ao crescimento, computando o percentual de abertura de gemas após 21 dias ou o número de dias necessários ao desenvolvimento de certa percentagem fixa, porém arbitrária, de gemas. (Citadini et al., 2002).

Os efeitos adversos da insuficiência em frio são: decréscimo na produção, sabor amargo e exsudação de gomas nos frutos, ruptura dos caroços e atraso no amadurecimento dos frutos, resultando em competição no mercado com cultivares de regiões mais frias (Lammerts, 1941), além disto os frutos são pequenos e mal formados (Bowen, 1971).

A ocorrência de geadas fortes e tardias é um fenômeno que tem de ser levado em consideração, já que pode comprometer a produção das frutíferas como pessegueiro e a nectarineira. As frutíferas de clima temperado apresentam gemas bastante resistentes às baixas temperaturas que lhe são benéficas para a quebra de dormência. No entanto, os frutos novos são muito sensíveis, caindo quando expostos à temperatura de congelamento. Evidentemente, os locais muito sujeitos a granizo, ou mesmo a rajadas de vento frio, devem ser sempre que possível evitados. (Ojima et al., 1984).

O pessegueiro desenvolve-se bem em solos profundos e bem drenados, as raízes necessitam de boa aeração para realizarem as suas atividades, sendo que o acúmulo de água possui efeito drástico na planta, principalmente no início da brotação e na estação de crescimento. Quanto à textura, têm-se como ideais, solos de textura média, devendo a argila situar-se em torno de 30 a 35\%. O pH mais favorável situa-se ao redor de 6,0. Recomenda-se não plantar em locais onde o pessegueiro anteriormente tenha sido cultivado, pois compostos tóxicos emanados pelas raízes do cultivo anterior impedem o crescimento ou causam a morte das plantas novas. (Herter et al., 1998)

\subsection{Carboidratos}

Os carboidratos são definidos quimicamente, como poli-hidróxi-cetonas (cetoses) ou poli-hidróxi-aldeídos (aldoses), ou seja, compostos orgânicos com pelo menos três carbonos onde todos os carbonos possuem uma hidroxila, com exceção de um, que possui a carbonila primária (grupamento aldeídico) ou a carbonila secundária (grupamento cetônico). Possuem fórmula empírica $\mathrm{C}_{\mathrm{n}}\left(\mathrm{H}_{2} \mathrm{O}\right)_{\mathrm{m}}$ desde os mais simples (os 
monossacarídeos, onde $n=m$ ) até os maiores (com peso molecular de até milhões de daltons). Alguns carboidratos, entretanto, possuem em sua estrutura nitrogênio, fósforo ou enxofre não se adequando, portanto, à fórmula geral.

A água é a principal substância translocada via floema, representando $98 \%$ do total, sendo que os 2 \% restantes compõem-se de solutos orgânicos e não orgânicos. Destes solutos, 98\% são açucares e 2\% outras substâncias (compostos nitrogenados, ácidos orgânicos, aminoácidos, ATP, reguladores de crescimento, etc.). Os solutos orgânicos são compostos de sacarose (99\%), verbascose, rafinose, estaquiose, etc.

Resumidamente, ao incidir a luz nas folhas, ocorre a fotossíntese, tendo como produto à hexose (podendo ser glucose ou frutose). Em pH básico ou neutro, com a ação da enzima amilofosforilase, esta hexose acumula-se, na forma de amido. Já em pH básico, com a ação da invertase, as hexoses transformam-se em sacarose, que são transportadas via floema para as regiões de dreno, podendo ser estas regiões ativas, como desenvolvimento de ramos, flores, frutos, etc., ou em regiões de armazenamento correspondentes aos tecidos de reserva, presentes nas raízes ou ramos. (Castro, 1985).

Durante o crescimento e desenvolvimento das plantas, os açucares participam de uma gama de processos vitais como germinação de sementes, desenvolvimento de plântulas, diferenciação radicular e foliar, transição foliar, amadurecimento de frutos, embriogênese, senescência, assim como respondem às variações de luz, estresse e patógenos (León \& Sheen, 2003). O armazenamento de carboidratos é necessário para sustentar o desenvolvimento das plantas em períodos de estresse, durante a dormência, e muito importante no início de crescimento e frutificação na primavera. As reservas de carboidratos não estruturados, em frutos de caroço, mudam qualitativa e quantitativamente durante os estádios de crescimento dos frutos e nas plantas durante as estações de crescimento (Faust, 1989)

Em rosáceas, a maior parte do carbono fixado na fotossíntese é armazenado na forma de amido no cloroplasto ou é transferido ao citossol e convertido nos carboidratos solúveis sacarose e sorbitol (Quick \& Schaffer, 1996). Apenas traços de outros carboidratos são encontrados, como a rafinose, a estaquiose e o monoisitol (Salisbury \& Ross, 1992). Desde a década de 1960, o sorbitol tem sido determinado como o principal 
assimilado translocado na macieira (Williams et al., 1967) e mais recentemente, em outras rosáceas, como a pereira (Herter et al., 2001) e o pessegueiro (Marquat et al., 1999).

O amido e a sacarose são os principais carboidratos formados na fotossíntese. O primeiro é imóvel, sendo sintetizado nos cloroplastos dos órgãos fotossintetizantes, e nos amiloplastos dos órgãos não fotossintetizantes. O segundo é móvel e é sintetizado nos citosol das células e descarregado no floema. A sacarose, por ser móvel, é o principal substrato para a respiração que mantém o vegetal vivo e ativo. Uma vez translocada a locais não fotossintetizantes, como as raízes, a sacarose é rapidamente convertida em frutose e glicose por enzimas invertases. Nestes órgãos, os carboidratos mais simples formados podem ser utilizados de três formas: a) na respiração, para a formação de ATP e outros compostos importantes; b) ser armazenados no vacúolo para posterior uso na respiração; e c) a glicose pode ser convertida em amido, servindo com reserva para uso em situações onde há pouca atividade fotossintética da parte aérea (Taiz \& Zeiger, 2002).

De uma forma geral, os açucares solúveis que proporcionam a energia necessária para o metabolismo da planta, são derivados da hidrólise do amido dos tecidos de reserva por ação de enzimas hidrolíticas.

\subsection{Poda em Pessegueiros}

A poda do pessegueiro requer conhecimentos relativos à própria planta e a cultivar. Deve-se ter em mente também, os objetivos a serem alcançados. Não há uma regra invariável para a poda, sendo necessário antes de tudo, bom senso e conhecimento dos seus princípios e finalidades, e do hábito de frutificação da planta. (Raseira et al., 1999)

Segundo Fuertes \& Hernández (1995), a poda é uma prática de cultivo que consiste em conduzir as plantas, modificando seu desenvolvimento natural. Objetiva-se equilibrar sua capacidade vegetativa e produtiva, obtendo-se maior produção com frutos de alta qualidade, distribuídos de forma uniforme pela totalidade da copa, obtendo 
plantas de tamanho adequado para executar de forma funcional os trabalhos de condução e manejo do pomar.

Gato \& Horta (1999), descrevem algumas desvantagens que a pratica da poda pode resultar, como redução da longevidade das plantas, devido aos danos provocados pelos cortes; desequilíbrio que é produzido entre as raízes e a parte aérea das plantas devido a modificação do volume da copa e o custo econômico necessário para a realização desta.

Faust (1989) considera que a poda diminui efetivamente o tamanho da árvore, mudando conseqüentemente seu dossel, e induzindo assim, alteração em suas reservas de carboidratos. O autor verificou que o metabolismo de carboidratos, especialmente durante o início de crescimento, foi diferente em plantas podadas e não podadas.

A época apropriada para a realização da poda é durante o período de repouso. Não deve ser muito cedo a fim de se evitar um estímulo à brotação precoce, nem muito tarde, para se prevenir à perda de reservas com a brotação eliminada pela poda (Pereira et al., 1984).

Devido a sua biologia, o pessegueiro constitui uma espécie em que a poda anual de frutificação se torna obrigatória. A frutificação só ocorre em ramos do ano anterior. Depois dela, o ramo perde sua função, e se não for podado, será apenas uma ponte entre a raiz e a parte superior da copa. Essa situação obriga a planta a frutificar cada vez mais distante opondo, com isso dificuldades à nutrição (Simão, 1998).

Na poda de frutificação, visa-se deixar um número limitado e equilibrado de ramos vegetativos e frutíferos e manter a forma da copa, interferindo-se na tendência natural da planta de crescer demasiadamente em altura. (Raseira et al., 1998).

Diversos tipos de podas de verão podem ser utilizados (Marini, 1985; Barbosa et al., 1999, Scarpare Filho et al., 1999.). No Estado de São Paulo, tem-se utilizado a poda de renovação, que consiste na poda após a colheita de frutos, de todos os ramos da planta, que produziram ou não. Em nossas condições, após a poda, ocorre a brotação, iniciando assim, o crescimento vegetativo e a diferenciação das gemas para a safra seguinte. Nienow (1997) comparou dois sistemas de podas: a tradicional, realizado no final da dormência e a poda de renovação, realizada após a colheita. Verificou que a 
poda de renovação realizada no final da primavera, embora tenha retardado a derrubada das folhas e evitado o florescimento no final do verão, afetou a produtividade do pomar. Porém, Marini (1985) estudando podas em plantas dormentes e podas de verão, não constatou nenhuma diferença na produção, tamanho de frutos e época de maturação, nos diferentes tratamentos.

Raseira et al. (1998), afirma que nas plantas em produção, a poda verde é realizada com a finalidade de suprimir os ramos nos quais o crescimento está dirigido para o interior da copa, ampliando a aeração e a iluminação no interior da planta, promovendo um aumento de frutificação nas camadas inferiores dos ramos e melhorando a coloração da película dos frutos. Já Campo Dall’Orto et al., (1984), relatam que na formação de pomares compactados de pessegueiros, as plantas são conduzidas mais livremente, apesar do maior adensamento, pois serão podadas drasticamente logo após a colheita, reconstituindo-se nova copa a cada ciclo produtivo.

De qualquer forma, a poda em pessegueiro já está previamente estabelecida e tem como um dos objetivos principais manter o equilíbrio entre o desenvolvimento vegetativo e reprodutivo, evitando assim a alternância de safras e reduzindo o trabalho de raleio (Callesen \& Wagenmakers, 1989; Olien, 1992; Dejong et al., 1992; Campo Dall'orto et al., 1991).

\subsection{Qualidade de Frutos}

Os frutos são valorizados pelo homem, muitas vezes devido a seu sabor, aparência e textura. Em todas as propriedades, os açucares direta ou indiretamente tem um papel importante. O sabor é fundamentalmente o balanço entre açucares e ácidos e em alguns casos, seus constituintes específicos são glicosídios. Cores atraentes de muitos frutos resultam de açucares derivados de antocianidinas. A textura é governada por polissacarídeos estruturais e o acido ascórbico (vitamina C), abundante em frutos é considerado um derivativo de açúcar. (Hulme, 1970).

$\mathrm{Na}$ literatura, trabalhos que caracterizam a qualidade dos frutos de diversos cultivares de pêssego enfatizam os atributos físicos e químicos dos frutos como: coloração da casca e polpa; formato; comprimento; diâmetro e peso do fruto; firmeza da 
polpa; presença de auréola em torno do caroço; acidez e teores de sólidos solúveis, entre outros. (Albuquerque, 1997)

A sacarose é o principal açúcar translocado das folhas para os frutos. Enquanto uma parte translocada de açucares para os frutos jovens é usada na síntese de pectinas e outros materiais estruturais de membranas, uma parte é convertida num produto usual de armazenamento que é o caso do amido. (Hulme, 1970)

As principais mudanças anatômicas durante o amadurecimento são a degradação da parede celular e da lamela média pela ação das enzimas pectolíticas, provocando um amaciamento no tecido, e a transformação de cloroplastos em cromoplastos, o que resulta na modificação da coloração. Durante o amadurecimento, a coloração verde, chamada de cor de fundo, vai gradativamente dando lugar à amarela e vermelha. Este fato pode ser atribuído à degradação da clorofila e síntese de carotenóides (Bron, 2001).

A cor, além de ser importante por influenciar a preferência dos consumidores, esta diretamente relacionada com o valor vitamínico do fruto, devido aos pigmentos carotenóides. No pêssego, o $\beta$-caroteno, a luteína e a violaxantina são os pigmentos mais sintetizados no decorrer do período de amadurecimento (Katayama et al, 1971). As antocianinas são determinantes primários da qualidade dos frutos frescos e do potencial ornamental do pêssego (Chaparro et al., 1995)

Além da perda da firmeza, várias modificações químicas podem ser associadas ao amadurecimento, como alterações nos teores de sólidos solúveis totais, na coloração e na acidez (Tonutti et al., 1996)

Brooks et al., (1993), observaram que os conteúdos de glicose, frutose, sorbitol, sólidos solúveis e acidez diferiram significativamente em dois anos de colheita, enquanto o conteúdo de sacarose e a concentração de açucares totais não mostraram variação anual significativa. Estudos sobre a maturação dos frutos revelaram que não ocorrem mudanças significativas nos teores de sólidos solúveis, nas percentagens de glicose e frutose e no conteúdo de açúcar total durante o amadurecimento dos frutos na planta. A acidez e a percentagem de sorbitol decrescem, enquanto a relação açúcar/acidez e a percentagem de sacarose aumentam com a evolução da maturação. 
Na maioria dos frutos, constata-se quantias extremamente pequenas de açucares livres que não sejam glicose, frutose ou sacarose. Podem ocorrer inter-conversões de açucares que estão muito mais ligadas a reações a partir de ésteres fosfatados ou açucares nucleotídicos do que açucares livres. (Hulme, 1970)

Os sólidos solúveis são usados como índice de açucares totais em frutos, sendo responsáveis pela doçura, através do balanço com os ácidos, e indicam o grau de maturação dos frutos. Os sólidos solúveis totais são constituídos por compostos solúveis em água como ácidos, vitamina C, aminoácidos, algumas pectinas e principalmente por açucares (glicose, frutose e sacarose), que perfazem de 65 a 85\% do total. Normalmente o teor de sólidos solúveis aumenta com o progresso do amadurecimento devido aos processos de biossíntese ou degradação de polissacarídeos (Botrel et al., 1993). De acordo com Liverani \& Cangini (1991), a sacarose é o principal açúcar presente nos frutos de pêssego maduros.

Raseira \& Nakasu, descrevem um sabor doce-ácido para o cultivar “Flordaprince’, apresentando valores no teor de sólidos solúveis de 8 a 9,5 Brix, podendo em casos raros alcançar $11^{\circ}$ Brix.

\subsection{Ferrugem}

Um problema decorrente do plantio de pessegueiros em locais de clima mais quente como no Estado de São Paulo, foi o aumento considerável da importância da ferrugem, causado pelo fungo Tranzschelia discolor, doença de importância esporádica em regiões temperadas. As condições climáticas favoráveis à incidência deste patógeno, aliadas à inexistência de um controle químico eficiente, tornaram essa doença, a mais preocupante em várias regiões produtoras de pêssego, onde devido à desfolha precoce, causa perdas significativas na produção a cada ano. (Martins \& Amorim, 1996).

O agente causal da ferrugem do pessegueiro (Prunus persica L. Batsch) é o fungo Tranzchelia discolor (Fuckel) Tranzchek \& Litinov, que já foi relatado também como patógeno de plantas de nectarina (Prunus persica var. nucipersica), damasco (P. 
armeniaca L.), amêndoa (P. dulcis (Mill.) Webb), ameixa européia (P. domestica L.) e ameixa japonesa (P. salicina Lindl.) (Kable et al.,' citados por Martins, 1999).

A doença se caracteriza pela formação, na face inferior da folha, de pústulas arredondadas recobertas de massa pulverulenta de esporos de fungo; estes são de cor amarela, correspondendo aos uredósporos, ou de cor parda quando correspondem aos teliósporos. Na face superior da folha, em correspondência com a pústula, formam-se manchas de cor amarelo pálido. (Anderson, 1956; Pizza Júnior \& Braga, 1970).

Nos frutos, causa manchas redondas deprimidas, de coloração esverdeada. Nos ramos, origina bolhas ovais no início da primavera. (Pizza Júnior \& Braga, 1970).

Em fruteiras de clima temperado, a ocorrência e severidade de uma doença estão também condicionadas ao estado nutricional das plantas, à localização da cultura, ao tipo de resistência genética das cultivares e a diversidade das espécies no espaço em que se inserem no pomar (Steinberg, 1989).

Sutton, (1988), cita que as variáveis climáticas que mais influenciam o processo de infecção são temperatura e umidade. Em doenças foliares e em condições de campo é muito difícil separar a influência da temperatura da influência da umidade, devido à interação entre elas, podendo-se citar como exemplo o fato do teor de umidade atmosférica na superfície das folhas dependerem rigorosamente da temperatura. (Zentmyer \& Bald, 1977).

Para a ferrugem do pessegueiro, ha uma afirmação generalizada de que os períodos quentes e úmidos, freqüentes nas áreas subtropicais, nos meses de setembro a abril, são os mais favoráveis para a infecção. Segundo Bleicher \& Tanaka (1982), epidemias de ferrugem podem ocorrer em anos chuvosos e com temperaturas elevadas. A duração do período de molhamento necessário para a infecção por Tranzchelia discolor a diferentes temperaturas é desconhecida, embora saiba-se que um período 18 horas de molhamento a $20^{\circ} \mathrm{C}$ é suficiente para uma infecção severa (Ogawa et al., 1995).

1 KABLE, P.F.; ELLISON, P.J.; BAMBAXH, R.W. Physiologic speciaization of Tranzschelia discolor in Australia. Plant Disease, v. 70, n. 3, p. 202-204, 1986. 
Apesar dos prejuízos que a doença pode causar, o controle da ferrugem do pessegueiro está restrito a poucas práticas culturais complementares, como a realização de boa limpeza do pomar por meio de podas, eliminação de folhas e ramos infectados e tratamentos de inverno.

O controle químico é a medida mais usada, porém se mostra deficiente, já que há pouquíssimos fungicidas registrados para a cultura. Esses produtos, além de não serem registrados para o controle da ferrugem especificamente, nem sempre fornecem controle satisfatório. (Martins, 1994).

Nas regiões subtropicais, a queda precoce das folhas pode provocar uma segunda floração no outono, com prejuízos consideráveis à planta, uma vez que essa florada não será aproveitada e a planta gasta muita energia para emiti-la, além do armazenamento de nutrientes já estar comprometido pela ausência das folhas, órgãos sintetizadores. (Bleicher \& Tanaka, 1982).

Em casos de alta severidade da doença, que ocorre principalmente no final do ciclo, abscisão foliar resultando em desfolha parcial ou quase completa da planta pode ser observada. (Martins \& Amorim, 1996). Isto prejudica os pessegueiros cultivados em regiões tropicais, pois é neste período que ocorre o acúmulo de fotoassimilados. Um dos métodos culturais realizados pelos produtores para o manejo da ferrugem (Tranzschelia discolor), consiste na poda de renovação do pomar, logo após a colheita dos frutos.

A poda de renovação emite novas brotações e mantém as folhas por mais tempo. Porém, quando esta não é realizada, ocorre um aumento de desfolha devido à presença da ferrugem em folhas maduras, sendo necessário um elevado número de pulverizações para a manutenção destas folhas e conseqüentemente armazenamento de reservas para a safra seguinte. 


\section{MATERIAL E MÉTODOS}

\subsection{Caracterização da Área Experimental}

O projeto de pesquisa foi conduzido na área experimental do Departamento de Produção Vegetal da Escola Superior de Agricultura “Luiz de Queiroz” (ESALQ-USP), em Piracicaba-SP.

O clima da região, conforme a classificação de Köppen, é do tipo Cwa: tropical de altitude, com três meses mais secos (junho/julho/agosto), chuvas de verão e seca no inverno. A temperatura média no mês mais quente é maior do que $22^{\circ} \mathrm{C}$ e do mês mais frio não é inferior a $16^{\circ} \mathrm{C}$, com média de $21,1^{\circ} \mathrm{C}$, precipitação média de $1253 \mathrm{~mm} / \mathrm{ano}$, umidade relativa do ar de 74\% e insolação mensal de 201,5h. Dados climatológicos de Piracicaba, coletados no período de 2003/2004, estão descritos no Apêndice 1.

O solo da área experimental é classificado como Terra Roxa Estruturada Eutrófica A moderado textura argilosa, correspondendo ao Argissolo Vermelho Eutrófico, de acordo com o Sistema Brasileiro de Classificação de Solos da Embrapa (Embrapa, 1999.)

O experimento foi constituído por 96 plantas, cultivar Flordaprince, enxertadas sobre pessegueiros 'Okinawa', implantadas no mês de agosto de 2001, em espaçamento de 3,0 X 1,2 m, sendo conduzido sob sistema de líder central, o que corresponde a 2777 plantas/hectare. As coordenadas geográficas da área do experimento são: latitude: $22^{\circ} 42.603^{\prime}$; longitude: $47^{\circ} 37.625^{\prime}$ e altitude de $520 \mathrm{~m}$. 


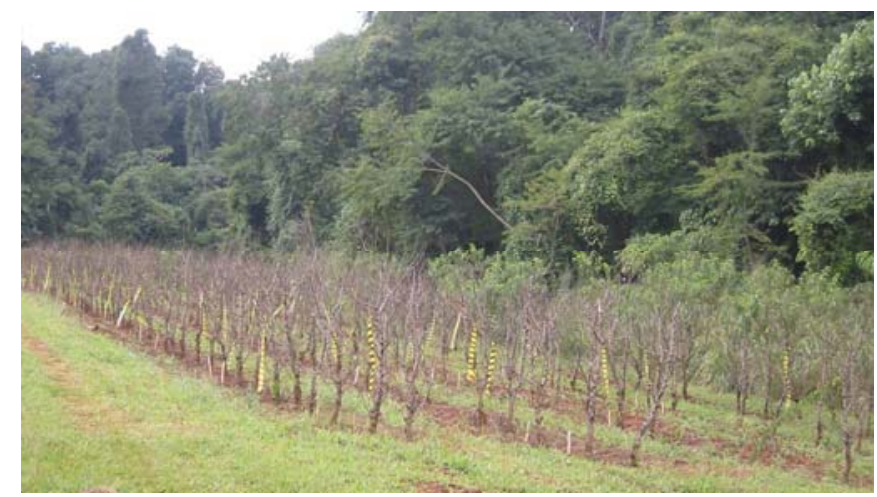

Figura 1 - Área experimental em fase de dormência

\subsection{Tratamentos}

\subsubsection{Sistemas de Poda}

Foram utilizadas para todos os tratamentos a poda seca (frutificação), no mês de junho (Figura 1) e duas intensidades de poda verde, após a colheita dos frutos, denominados de poda leve (PL) e poda drástica (PD).

A poda leve (PL), consiste na eliminação dos ramos que já produziram, os mal posicionados e as brotações em excesso. A poda drástica (PD) consiste na remoção de todos os ramos que produziram ou não. (Figura 2).

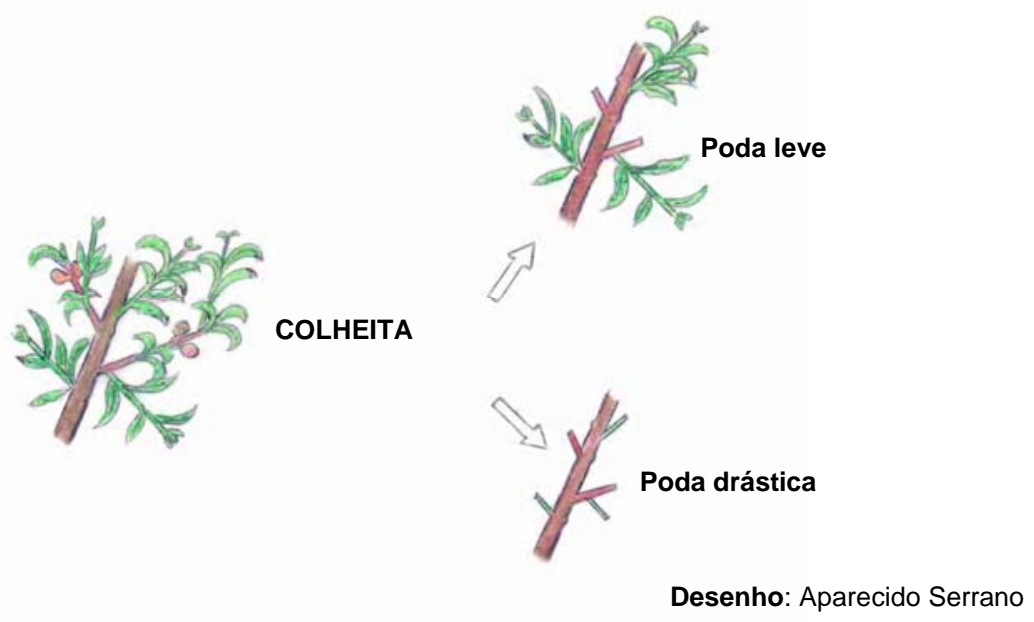

Figura 2 - Ilustração das intensidades de poda verde utilizadas após a colheita dos frutos 
Os tratamentos foram duas intensidades de poda verde:

T1- poda leve após a colheita dos frutos (PL);

T2- poda drástica após a colheita dos frutos (PD);

\subsection{Variáveis Analisadas}

Acompanhou-se o desenvolvimento vegetativo e reprodutivo do pessegueiro nos ciclo de produção, referente à safra 2003/04, onde foram analisadas as seguintes variáveis:

\subsubsection{Florescimento Efetivo}

Foi avaliado o florescimento efetivo de pessegueiros sendo que em maio de 2004, foram escolhidas quatro plantas de pessegueiro, por tratamento e repetição, totalizando 96 plantas onde foi marcado um ramo por planta de preferência a 1,5 m de altura, sendo contado o número de gemas floríferas. O monitoramento do número de flores originadas no ramo foi realizado até o mês de julho de 2004.

Para o cálculo do florescimento efetivo, foi utilizada a seguinte fórmula:

$$
\text { número de flores originadas }
$$

Florescimento efetivo $=$

$$
\text { número de gemas floríferas contadas }
$$

Raseira \& Nakasu (1998), caracterizam o cultivar 'Flordaprince' como sendo de vigor médio e relatam a presença de 8 a 10 pares de gemas floríferas a cada $25 \mathrm{~cm}$ de comprimento de ramo.

\subsubsection{Densidade de Brotação}

Foi avaliada a densidade de brotação de pessegueiros sendo que em maio de 2004, foram escolhidas quatro plantas de pessegueiro, por tratamento e repetição, totalizando 96 plantas onde foi marcado um ramo por planta de preferência a 1,5 m de 
altura, sendo contado o número de gemas vegetativas. O monitoramento do número de brotações originadas no ramo foi realizado até o mês de julho de 2004

Para o cálculo da densidade de brotação, foi utilizada a seguinte fórmula:

Densidade de brotação $=\frac{\text { número de brotações originadas }}{\text { número de gemas vegetativas contadas }} \times 100$

\subsubsection{Crescimento de Ramos}

Foi monitorado o crescimento de ramos, após a brotação da poda seca. Foi monitorado também o crescimento de ramos após a realização das intensidades de poda verde estudadas.

Em novembro de 2003, após a prática das intensidades de poda estudadas (PL) e (PD) e com a emissão de novas brotações, realizou-se o monitoramento do desenvolvimento em centímetros dessas brotações em quatro ramos por tratamento e repetição a cada 7 dias, até o mês de dezembro de 2003.

Em julho de 2004, escolheu-se uma brotação de forma aleatória em quatro ramos por tratamento e repetição, onde foram monitorados a densidade de brotação. Avaliou-se o desenvolvimento em centímetros do ramo a cada 7 dias, até o mês de setembro. Os ramos monitorados foram divididos de acordo com a inserção no ramo do ano anterior, sendo classificados em basais, medianos e apicais.

\subsubsection{Desenvolvimento dos Frutos}

O desenvolvimento de frutos foi avaliado medindo-se com o uso de um paquímetro digital marca Digimess (Figura 3b), o comprimento e o diâmetro dos frutos em mm.

Em julho de 2004, escolheu-se um fruto, de forma aleatória para cada tratamento e repetição nos ramos onde foram monitorados o florescimento efetivo, sendo avaliados o comprimento e diâmetro a cada sete dias, até a realização da colheita. 

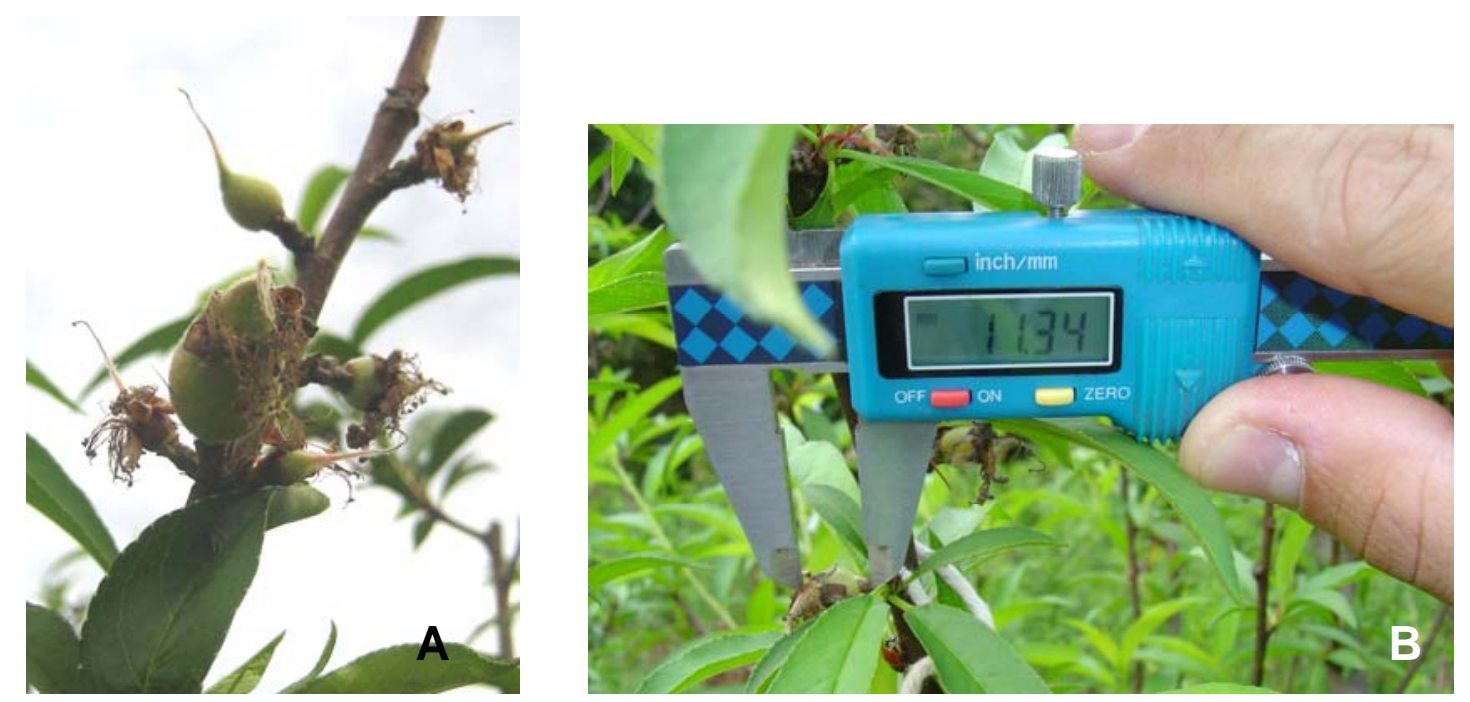

Figura 3 - Início da frutificação (A) e avaliação inicial do comprimento e diâmetro de frutos (B)

\subsubsection{Qualidade dos Frutos}

\subsubsection{Massa e Tamanho dos Frutos}

Para o ano de 2004, a colheita foi realizada no período de 14 a 26 de setembro, onde foram determinados o número de frutos e a massa média por tratamento e repetição. A massa média dos frutos foi obtida pela divisão da massa total colhida por tratamento e repetição pelo número de frutos. A medição do comprimento e diâmetro médio foi efetuada em 15 frutos por tratamento e repetição.

\subsubsection{Coloração}

Foi avaliada a coloração da epiderme em dois locais distintos de cada fruto, correspondente onde a coloração é mais acentuada em decorrência da maior exposição ao sol (face exposta) e a coloração de fundo. A determinação foi realizada em 5 frutos por tratamento e repetição, com o uso de um colorímetro Minolta CR-300, Osaka, Japan. A leitura foi realizada em sistema $\mathrm{L}^{*} \mathrm{a}$ b e os resultados foram transformados em ângulo de cor (H), segundo McGuire (1992). Considerou-se o valor médio das leituras por tratamento e repetição. 


\subsubsection{Firmeza da Polpa}

Após a remoção de uma parte da epiderme, foi avaliada a firmeza da polpa dos frutos na região equatorial, perpendicular a sutura. A determinação foi realizada em 5 frutos por tratamento e repetição, com o uso de um penetrômetro digital 53200 - Samar, Tr (Turoni, Forti, Italy), com ponteira de $8 \mathrm{~mm}$ de diâmetro, sendo os resultados expressos em Newtons $(\mathrm{N})$. Considerou-se o valor médio das leituras por tratamento e repetição.

\subsubsection{Teor de Sólidos Solúveis $\left({ }^{\circ} \mathrm{Brix}\right)$}

Após a retirada de uma parte da polpa do fruto, utilizando-se um espremedor manual, uma gota de suco foi colocada sobre o prisma de um refratômetro digital Atago PR-101, (Atago Co Ltda, Tókio, Japan), onde a leitura foi feita em ${ }^{\circ}$ Brix, com correção da temperatura para $20^{\circ} \mathrm{C}$. A determinação foi realizada em 5 frutos por tratamento e repetição, considerando-se o valor médio das leituras.

\subsubsection{Severidade de Ferrugem}

No período de dezembro de 2004 a janeiro de 2005, após a brotação da poda verde, avaliou-se em 4 ramos de pessegueiro por tratamento e repetição, a severidade de ferrugem de acordo com a escala diagramática. (Figura 4).

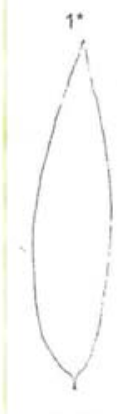

$0 \%$

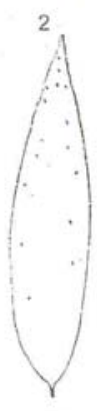

$0,8 \%$

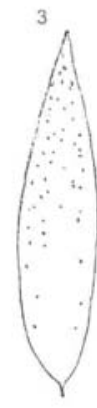

$2.4 \%$
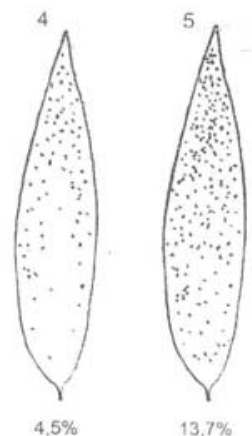

Figura 4 - Escala diagramática para avaliação da severidade da ferrugem (Tranzschelia discolor) em folhas. (Martins, 1994 - modificada) 
Novas brotações foram escolhidas preferencialmente a uma altura de 1,50 m e a partir da pernada principal, para que fosse efetuada a avaliação da severidade de ferrugem a cada sete dias nos dois tratamentos, comparando-se folhas em um mesmo estágio de desenvolvimento e portanto com a mesma idade.

Desta forma, foram contados em cada ramo, o número total de folhas e atribuído notas para cada folha de acordo com a escala diagramática.

Azevedo (1997), comenta que vários autores consideram que a incidência não é um parâmetro preciso quando utilizado para avaliar doenças foliares, apesar de seu uso para tal fim. Por outro lado, a severidade é o parâmetro mais representativo para quantificar a doença, já que estima a relação entre a área lesionada da folha e a sua área total, e é de fundamental importância para a avaliação de doenças foliares, estabelecendo a intensidade real da doença na folha.

A severidade foi calculada através da média ponderada das notas atribuídas as folhas.

\subsubsection{Determinação das Concentrações de Carboidratos Solúveis}

Para a determinação das concentrações de carboidratos solúveis em raízes e ramos de pessegueiros, foram utilizados dados obtidos do ciclo de produção 2003/2004, correspondente aos meses de outubro de 2003 (após a colheita); dezembro de 2003 (desenvolvimento vegetativo); março de 2004 (início da queda das folhas); maio de 2004 (quebra de dormência); julho de 2004 (desenvolvimento vegetativo e início frutificação) e setembro de 2004 (colheita).

As amostras da parte aérea foram coletadas retirando-se segmentos de ramos lignificados, próximos à pernada principal (líder central). O tamanho das amostras coletadas variava entre 10 a $15 \mathrm{~cm}$.

As amostras de raízes foram coletadas retirando-se o solo em uma região radial de aproximadamente $40 \mathrm{~cm}$ distante da base da pernada principal, sendo retirados quase que a totalidade de segmentos de raízes de 5 a $10 \mathrm{~cm}$, encontrados nesta região, devido à dificuldade de homogeneização dessas amostras. 
Após a retirada de ramos e raízes, as amostras eram deixadas em estufa a $65^{\circ} \mathrm{C}$ por 96 horas, sendo depois trituradas em moinho elétrico modelo MA 680, com peneira de 0,8 mm e enviadas ao laboratório de Nutrição Animal do CENA/USP (Centro de Energia Nuclear na Agricultura) para determinação dos carboidratos solúveis.

Os carboidratos solúveis analisados são representados por frutose e glicose (açucares redutores), sacarose (carboidrato translocável) e amilase, que compõe o amido (carboidrato de reserva) sendo utilizado o método de fenol $+\mathrm{H}_{2} \mathrm{SO}_{4}$ (ácido sulfúrico), para sua determinação. Os dados foram expressos em (mg/100 ml em 100\% de matéria seca).
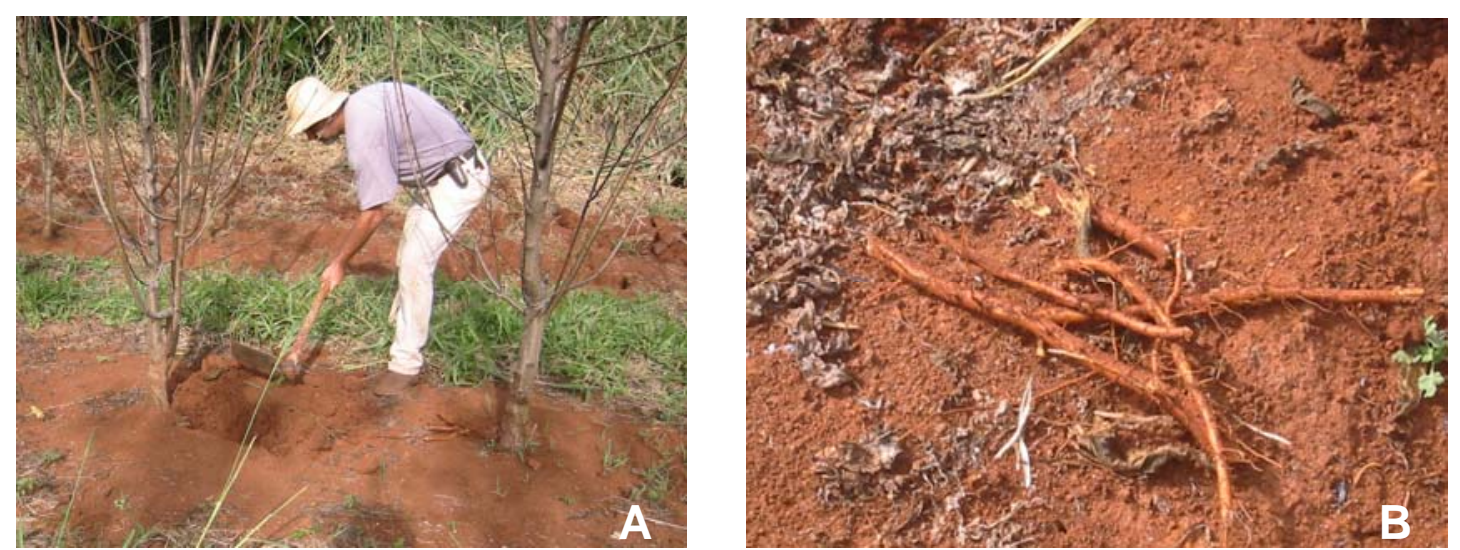

Figura 5 - Retirada de solo para coleta de raízes (A) e raízes amostradas (B)

\subsection{Delineamento Experimental}

O delineamento experimental para as duas intensidades de poda verde estudadas após a colheita dos frutos: poda leve (PL) e poda drástica (PD), foi distribuído inteiramente ao acaso na área do experimento, com 12 repetições, sendo quatro plantas por repetição. Os dados foram submetidos às análises de variância e à comparação das médias pelo teste de Tukey. O programa utilizado para a realização das análises estatísticas foi o ESTAT - Sistema para Análises Estatísticas (V. 2.0) - UNESP - FCAV - Campus de Jaboticabal. 


\subsection{Técnicas Culturais}

Durante a safra 2003/2004, todas as plantas receberam os tratos culturais, normalmente utilizados para a cultura do pessegueiro, como quebra de dormência, poda seca de frutificação, nutrição, irrigação, desbrotas, controle de invasoras e tratamentos fitossanitários. Foram realizadas análise de solo e de folhas para verificação do estado nutricional das plantas. (Apêndices 2 e 3)

Para a realização da análise foliar, foram coletadas folhas completas (limbo com pecíolo) na $13^{\mathrm{a}}$ semana após a plena floração, no dia 5 de outubro de 2004 . As folhas foram coletadas nos diferentes quadrantes das plantas, sendo retiradas quatro folhas por planta, somando duas plantas por repetição. As amostras foram divididas de acordo com os tratamentos em plantas PL e PD, sendo cada amostra composta por 96 folhas e enviadas ao laboratório do departamento de solos e nutrição de plantas da ESALQ-USP. 


\section{RESULTADOS E DISCUSSÃO}

\subsection{Florescimento Efetivo e Densidade de Brotação Após a Poda Seca}

O florescimento efetivo foi de $44,94 \%$ para plantas PL e de $34,52 \%$ para as plantas PD. O coeficiente de variação (CV) foi de 33,6. Não houve diferença estatística entre as médias observadas para as plantas PL e PD. Estes dados apresentam-se superiores aqueles observados por Marodin et al., (2002), que avaliando em duas épocas distintas, o efeito da cianamida hidrogenada e do óleo mineral na quebra de dormência de pessegueiros Flamecrest, obteve uma brotação média de gemas floríferas de 28,8\% em pomar comercial de quatro anos de idade no município de Farroupilha- RS.

Esta alta variabilidade de plantas submetidas à poda drástica, também foi observada por Barbosa (1989), que estudando o efeito em pessegueiros Aurora II e Tropical, conduzidos sob pomar compacto, observou um efeito supressivo no desenvolvimento de gemas floríferas de 19 a 74\%, diminuindo sensivelmente este tipo de gema por porção de ramo.

A densidade de brotação após a poda seca para as plantas PL foi de 86,86\% e de 81,26\% para as plantas PD. O coeficiente de variação (CV) foi de 16,63. Não houve diferença estatística entre as médias observadas para as plantas PL e PD. Desta forma, a poda verde realizada no mês de outubro, não interferiu na formação e brotação de gemas vegetativas, para o cultivar 'Flordaprince'. Esses dados são discrepantes dos observados por Barbosa, (1989), que verificou um efeito supressivo no desenvolvimento de gemas vegetativas de 10 a $62 \%$, diminuindo sensivelmente este tipo de gema por porção de ramo em plantas de pessegueiros Aurora II e Tropical, submetidas à poda drástica. 


\subsection{Crescimento de Ramos}

O crescimento de ramos, após a realização de poda verde efetuada em outubro de 2003, foi monitorado durante os meses de novembro a dezembro de 2003 (Figura 6).

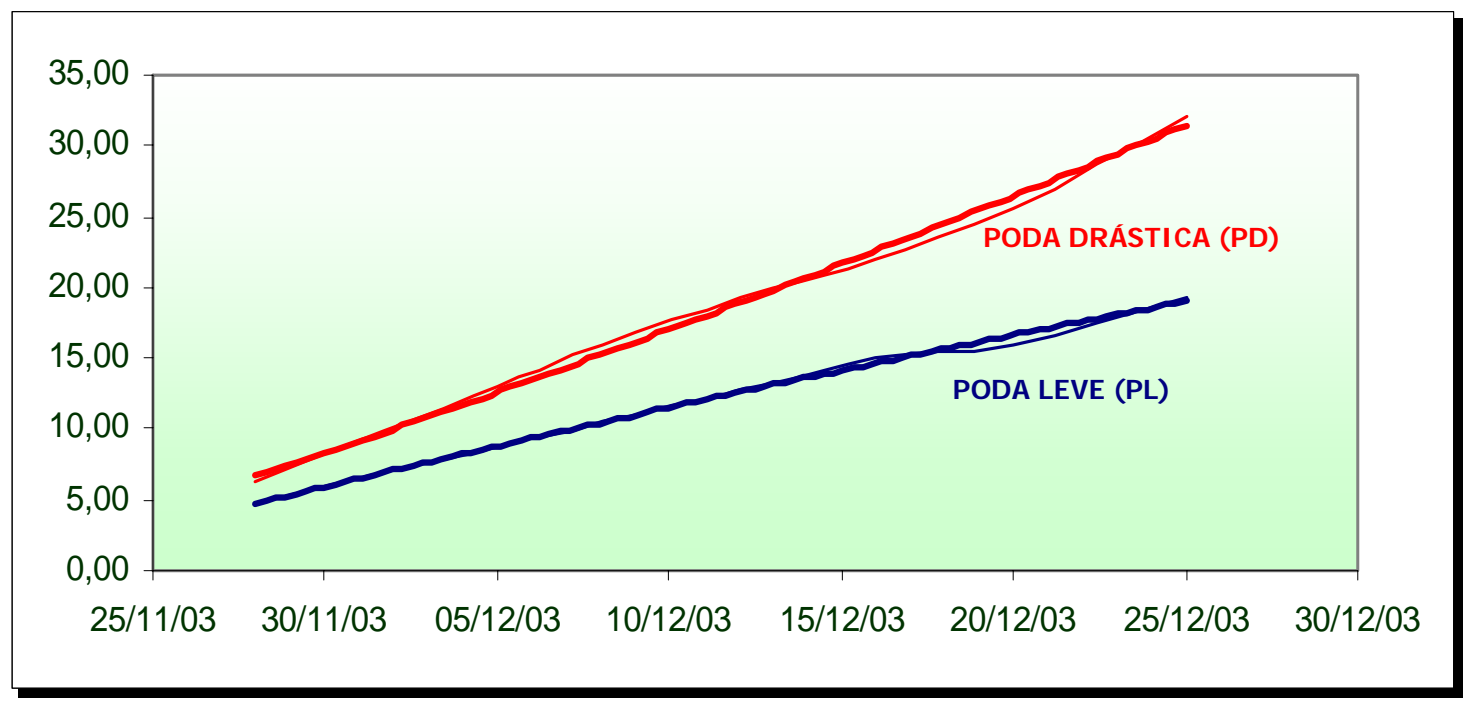

Figura 6 - Crescimento de ramos de pessegueiros 'Flordaprince' em plantas submetidas à diferentes intensidades de poda verde, Piracicaba 2005

Pode-se observar de acordo com a Figura 6, que plantas submetidas à poda drástica (PD), apresentaram um maior desenvolvimento dos ramos, quando comparadas a plantas que foram submetidas à poda leve (PL). Isto era esperado, pois autores como Fuertez \& Hernández, (1995), afirmam que a poda drástica geralmente provoca desenvolvimento de poucos ramos, porém vigorosos. Já a poda leve, produz muitos ramos de pouco vigor. Também são concordantes com o trabalho de Borba (2002), que trabalhando com plantas de pessegueiros Ouromel II, de cinco anos de idade, tratadas com poda drástica, apresentaram maior desenvolvimento vegetativo de ramos, quando comparadas com plantas que não receberam poda.

O crescimento de ramos após a poda seca ou “poda de inverno”, que ocorreu de julho a setembro de 2004, apresentou valores médios de 15,8 cm para plantas PL e $16,18 \mathrm{~cm}$ para plantas $\mathrm{PD}$, não se observando diferença estatística significativa entre os tratamentos. Isto ocorre, pois no período após a poda seca, o desenvolvimento 
vegetativo ocorre concomitantemente ao desenvolvimento dos frutos. Ramos e frutos competem neste período, pelas reservas e fotoassimilados da planta.

Porém, conforme a posição dos ramos nas plantas, observou-se diferenças no seu desenvolvimento. Para plantas PL, ramos da porção basal da planta, apresentaram valores médios de 16,18 cm, 10,8 cm para porção mediana e 20,7 para porção apical. Plantas PD apresentaram valores médios de 16,3 cm para porção basal, 14,3 cm para porção mediana e 27,7 cm para porção apical. Para os dois tratamentos estudados, ramos apicais tiveram um maior crescimento, diferindo estatisticamente dos ramos basais e medianos.

\subsection{Desenvolvimento de Frutos}

O desenvolvimento de frutos ocorreu no período de julho a setembro de 2004, concomitantemente ao crescimento dos ramos. Verificou-se para plantas PL que os frutos obtiveram a média 3,77 cm de comprimento e 3,57 cm de diâmetro. Plantas PD apresentaram valores médios de 4,11 cm de comprimento e 3,91 cm de diâmetro. Esses frutos caracterizam-se comercialmente como calibre 1, pois possuem o maior diâmetro transversal compreendido entre $(\geq 3,5 \mathrm{~cm}$ até $<4,5 \mathrm{~cm})$, de acordo com os critérios do Programa Brasileiro para Melhoria dos Padrões Comerciais e Embalagens de Hortigranjeiros.

O crescimento de frutos ocorreu de forma contínua e não como uma sigmóidedupla (Figura 7). 


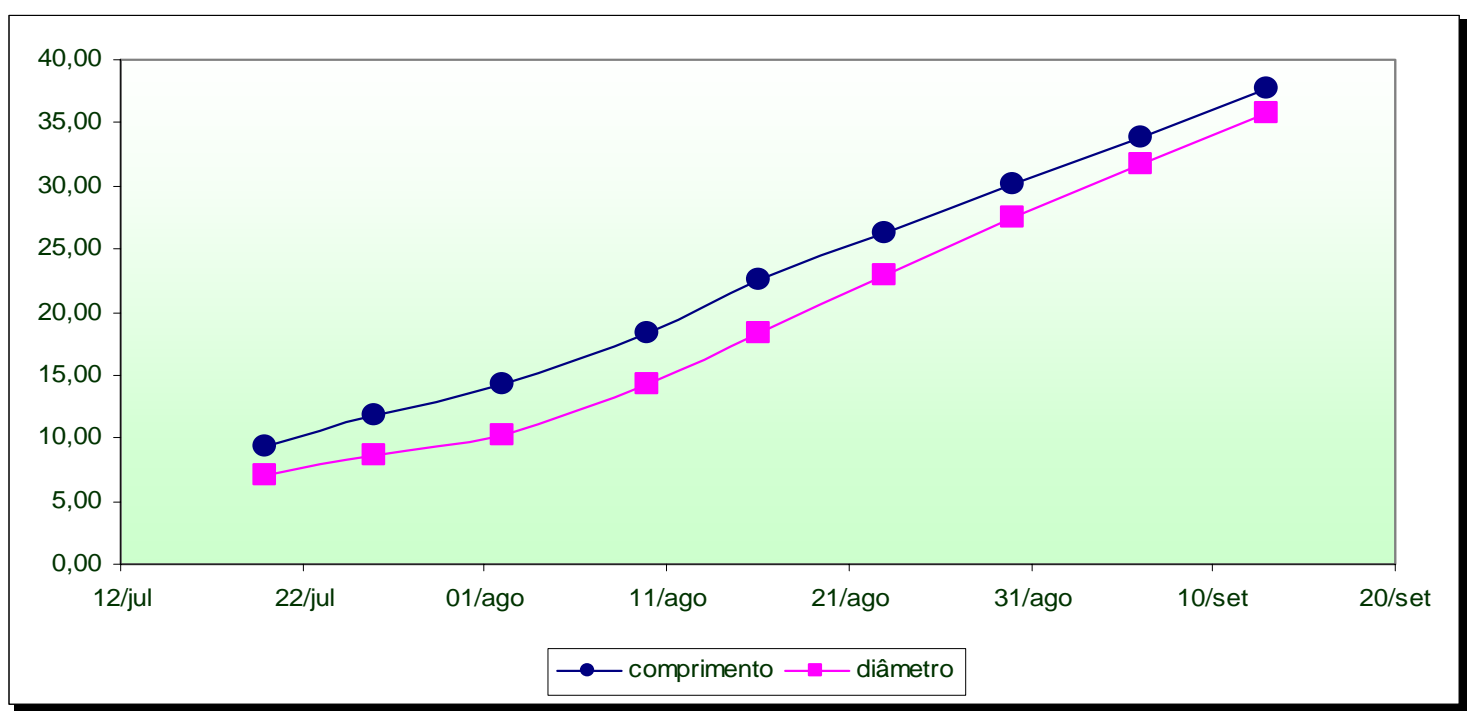

Figura 7 - Desenvolvimento dos frutos de pessegueiros ‘Flordaprince’, Piracicaba 2005

O desenvolvimento de frutos de pessegueiro é classificado por diversos autores como Powell \& Pratti, (1966); Zanchin et al. (1994) e outros, como sendo uma sigmóide-dupla que possui três fases: a primeira fase que é caracterizada pela multiplicação celular; a segunda fase pela paralisação de crescimento e endurecimento de caroço e a terceira fase de elongação celular.

Porém autores como DeJong \& Goudriann, (1989), questionam esse modelo de crescimento e consideram apenas duas fases de desenvolvimento de frutos. O modelo obtido no presente trabalho, está de acordo com o relatado por Agusti et al., (1997), que afirma que as fases de divisão e elongação celular se sobrepõem não sendo fácil detectálas em cultivares de desenvolvimento muito rápido, como é o caso do cultivar Flordaprince.

\subsection{Qualidade dos frutos}

\subsubsection{Massa e Tamanho dos Frutos}

A média do número de frutos colhido por planta, massa média de frutos, comprimento e diâmetro estão descritos na tabela 1. 
Tabela 1. Características de frutos de pêssegos ‘Flordaprince’ Piracicaba, 2005

\begin{tabular}{ccccc}
\hline Tratamento & $\begin{array}{c}\mathrm{N}^{\circ} \text { frutos/ } \\
\text { Planta }\end{array}$ & $\begin{array}{c}\text { Massa } \\
\text { Média }(\mathrm{g})\end{array}$ & $\begin{array}{c}\text { Comprimento } \\
(\mathrm{mm})\end{array}$ & $\begin{array}{c}\text { Diâmetro } \\
(\mathrm{mm})\end{array}$ \\
\hline PL* & $73.6 \mathrm{~A}$ & $46,2 \mathrm{~A}$ & $48.25 \mathrm{~A}$ & $45,71 \mathrm{~A}$ \\
PD** & $28.6 \mathrm{~B}$ & $49,3 \mathrm{~A}$ & $47,80 \mathrm{~A}$ & $45,08 \mathrm{~A}$ \\
CV & 59,43 & 18,87 & 9,04 & 7,59 \\
\hline
\end{tabular}

Médias seguidas por letras distintas em maiúsculo na coluna, diferem entre si pelo teste de Tukey ao nível de 5\% de probabilidade.

* PL = Poda verde de intensidade leve

** PD = Poda verde de intensidade drástica

Houve diferença estatística significativa entre os tratamentos no que se refere à quantidade de frutos colhidos por planta. Plantas (PL) apresentaram uma média de 73,6 frutos/planta e plantas (PD) uma média de 28,6 frutos/planta. Observa-se que as plantas (PL), produziram 2,6 vezes mais, quando comparadas às plantas (PD). Estes dados concordam com o trabalho de Borba, (2002), onde observou que plantas tratadas com poda leve produziram 2,03 vezes mais, quando comparadas com plantas submetidas à poda drástica em plantas de pessegueiros Ouromel II, com cinco anos de idade. Também Nienow (1997), verificou que a poda realizada no final da primavera, embora tenha retardado a derrubada das folhas e evitado o florescimento no final do verão, afetou a produtividade do pomar.

A redução da frutificação devido às podas excessivas, após a colheita, principalmente em plantas jovens e vigorosas, foi observada também por Hadlich \& Marodin, 2004.

Com relação a massa dos frutos, não houve diferença entre os tratamentos, observando-se baixos valores para esta variável, pois Raseira \& Nakasu (1998), relatam que para o cultivar 'Flordaprince’, a massa varia de 70 a $100 \mathrm{~g}$.

Não houve diferença significativa para comprimento e diâmetro de frutos de acordo com as duas intensidades de poda verde estudadas. 


\subsubsection{Coloração, Firmeza de Polpa e Teor de Sólidos Solúveis}

As médias de coloração, da firmeza da polpa dos frutos e do teor de sólidos solúveis, podem ser visualizadas na tabela 2.

Tabela 2. Qualidade dos frutos de pêssegos ‘Flordaprince’, Piracicaba 2005

\begin{tabular}{ccccc}
\hline Tratamentos & Firmeza & Sólidos Solúveis & \multicolumn{2}{c}{ Ângulo de cor (H) } \\
& (Newtons) & $\left({ }^{\circ}\right.$ Brix) & Face exposta & Cor de Fundo \\
\hline PL* & $58,8 \mathrm{~A}$ & $10,27 \mathrm{~A}$ & $41,43 \mathrm{~A}$ & $92,50 \mathrm{~A}$ \\
PD $^{* *}$ & $53,7 \mathrm{~A}$ & $9,00 \mathrm{~B}$ & $49,78 \mathrm{~A}$ & $96,47 \mathrm{~A}$ \\
CV & 23,19 & 14,05 & 19,11 & 29,08
\end{tabular}

Médias seguidas por letras distintas em maiúsculo na coluna, diferem entre si pelo teste de Tukey ao nível de 5\% de probabilidade.

* PL = Poda verde de intensidade leve

** PD = Poda verde de intensidade drástica

A intensidade de poda verde, além de afetar o número de frutos colhidos por planta, afetou também o teor de sólidos solúveis nos frutos. Plantas PL apresentaram teores mais elevados de sólidos solúveis nos frutos, em relação às plantas podadas drasticamente. Porém, com relação a firmeza e ao ângulo de cor dos frutos, não houve diferença entre os tratamentos.

Com relação ao ângulo de cor $(\mathrm{H})$, valores próximos a 0 (zero), representam o vermelho total, próximos a 90 o amarelo total e próximos a 180 o verde. De acordo com os dados apresentados, a coloração para a face exposta para plantas PL e PD estava entre o amarelo e o vermelho e a coloração da cor de fundo bem próximo ao amarelo total.

\subsection{Severidade de Ferrugem}

Os valores obtidos para a severidade de ferrugem de acordo com os tratamentos, durante o período de monitoramento da doença, podem ser visualizados na tabela 3. 
Tabela 3. Severidade de ferrugem para as diferentes intensidades de poda verde estudada em pessegueiros 'Flordaprince', Piracicaba 2005

\begin{tabular}{ccccccccc}
\hline Tratamentos & $06 / 12$ & $13 / 12$ & $20 / 12$ & $27 / 12$ & $03 / 01$ & $10 / 01$ & $17 / 01$ & $23 / 01$ \\
\hline PL $^{*}$ & 0,02 & 0,20 & 0,40 & 0,82 & 1,13 & 1,40 & 1,71 & 2,04 \\
PD $^{* *}$ & 0,00 & 0,12 & 0,37 & 0,80 & 1,12 & 1,48 & 1,76 & 2,08 \\
\hline
\end{tabular}

* PL = Poda verde de intensidade leve

** PD = Poda verde de intensidade drástica

A evolução da severidade da ferrugem em folhas de pessegueiro 'Flordaprince' ocorreu de forma semelhante, não havendo diferença significativa para as duas intensidades de poda verde estudadas. (Figura 8)

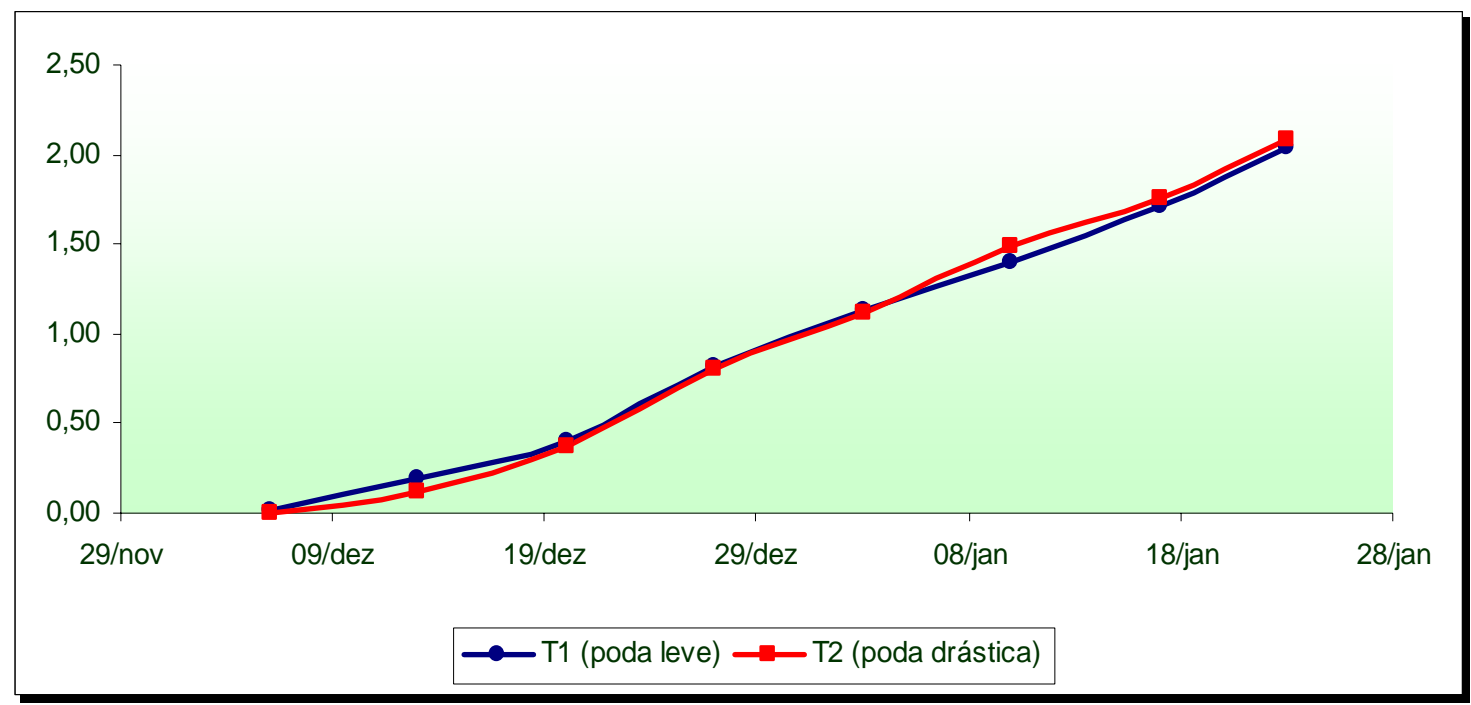

Figura 8 - Evolução da severidade de ferrugem (Tranzschelia discolor), em pessegueiros ‘Flordaprince’. Piracicaba, 2005

Verificou-se que a severidade de ferrugem aumenta com a idade das folhas. Esta observação explica porque uma das técnicas realizadas pelos produtores para o manejo da doença consiste em se realizar a poda drástica, após a colheita, retirando-se folhas maduras presentes na planta. Esta técnica diminui o inóculo inicial e, portanto atrasa a ocorrência da doença na planta. Isto não foi observado para o presente trabalho, uma vez 
que foram avaliadas novas brotações para as duas intensidades de poda verde estudadas, e com isso compararam-se folhas em um mesmo estágio de desenvolvimento.
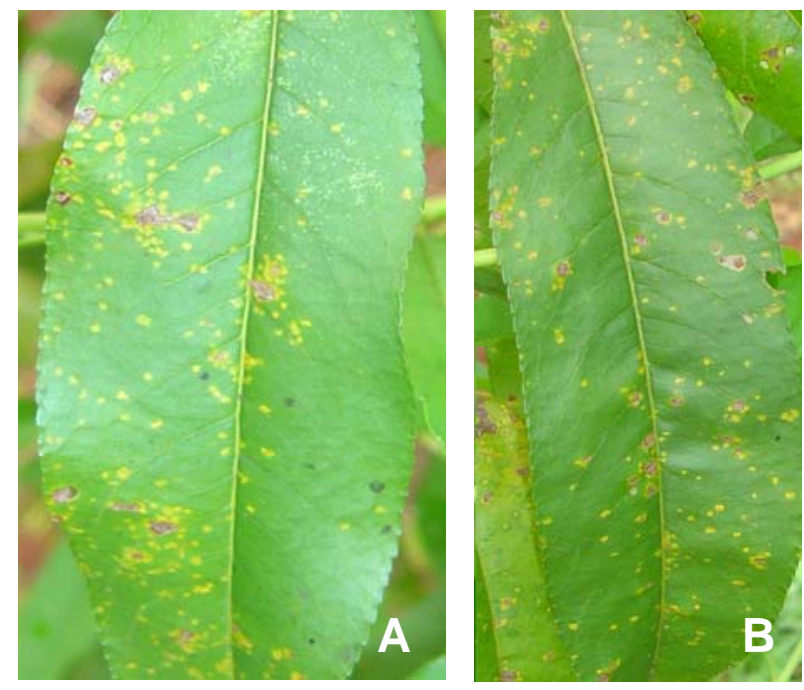

Figura 9 - Sintomas de ferrugem na face superior de folhas de pessegueiro (A) e (B)

\subsection{Determinação das Concentrações de Carboidratos Solúveis}

Os carboidratos solúveis analisados em raízes e ramos de pessegueiros (PL) e (PD), durante o período de outubro de 2003 a setembro de 2004 estão expressos na tabela 4. 
Tabela 4. Concentrações de carboidratos solúveis (mg/100ml em 100\% de matéria seca). em plantas (PL) e (PD), pessegueiro 'Flordaprince’ Piracicaba, 2005

\begin{tabular}{|c|c|c|c|c|c|c|}
\hline & Out/03 & Dez/03 & Mar/04 & Mai/04 & Jul/04 & Set/04 \\
\hline \multicolumn{7}{|c|}{$\mathrm{PL}^{*}$} \\
\hline Raízes & $194,57 \mathrm{~A}$ & $262,09 \mathrm{~A}$ & $199,06 \mathrm{~A}$ & $286,32 \mathrm{~A}$ & $213,66 \mathrm{~A}$ & $253,96 A$ \\
\hline Ramos & $103,96 \mathrm{~B}$ & $114,10 \mathrm{~B}$ & $95,31 \mathrm{~B}$ & 92,71B & $81,74 \mathrm{~B}$ & 63,77B \\
\hline \multicolumn{7}{|c|}{$\mathrm{PD}^{* *}$} \\
\hline Raízes & $194,57 \mathrm{~A}$ & $265,01 \mathrm{~A}$ & $233,38 A$ & $253,15 A$ & $234,86 \mathrm{~A}$ & $203,07 \mathrm{~A}$ \\
\hline Ramos & $103,96 B$ & $116,15 B$ & 95,64B & $84,21 B$ & $78,85 B$ & $62,56 \mathrm{~B}$ \\
\hline
\end{tabular}

Médias seguidas por letras distintas em maiúsculo na coluna, para o mesmo tratamento, diferem entre si pelo teste de Tukey ao nível de 5\% de probabilidade.

* PL = Poda verde de intensidade leve

** PD = Poda verde de intensidade drástica

Observou-se que as concentrações de carboidratos solúveis em raízes de plantas sempre apresentaram valores superiores aos ramos, independente da época e do tipo de poda realizado. Portanto as maiores quantidades de reservas da planta estão presentes nas raízes.

Pela tabela 5, podemos comparar as concentrações de carboidratos em raízes de acordo com as intensidades de poda verde estudadas. 
Tabela 5. Concentrações de carboidratos solúveis em raízes de plantas (PL) e (PD), em pessegueiros ‘Flordaprince’, Piracicaba 2005

\begin{tabular}{ccccccc}
\hline RAÍZES & Out/03 & Dez/03 & Mar/04 & Mai/04 & Jul/04 & Set/04 \\
\hline PL* $^{*}$ 194,57A & 262,09A & 199,06B & 286,32A & 213,66A & 235,96A \\
PD** & 194,57A & 265,01A & 233,38A & 253,15B & 234,86A & 203,07B
\end{tabular}

Médias seguidas por letras distintas em maiúsculo na coluna, diferem entre si pelo teste de Tukey ao nível de 5\% de probabilidade.

* PL = Poda verde de intensidade leve

** PD = Poda verde de intensidade drástica

Pode-se verificar que após a poda verde, inicia-se uma tendência de aumento nas concentrações de carboidratos solúveis em raízes até o mês de maio que corresponde à queda das folhas e final do ciclo de produção 2003/2004. Esta fase é considerada como o período em que as plantas acumulam reservas. Estes dados estão de acordo com o trabalho de Borba (2002), que observou um período de acúmulo de reservas nas raízes compreendido entre os meses de outubro a maio.

Porém, ocorreu uma oscilação nas concentrações de carboidratos no mês de março para os dois tratamentos. Isto pode ser devido, provavelmente, ao crescimento do sistema radicular no período.

Com a quebra de dormência e poda realizada no inicio de junho, estabeleceu-se o ciclo de produção 2004/2005. Pode-se verificar que as reservas das raízes foram utilizadas para o desenvolvimento inicial (crescimento de ramos e frutos). Com isso, houve um decréscimo nas concentrações de reservas das raízes que diminuíram sensivelmente neste período, maio a setembro. Este período foi denominado por Borba (2002), de mobilização de reservas.

Pode-se concluir que o desenvolvimento inicial de frutos e ramos ocorre praticamente através das reservas, principalmente das raízes, uma vez que a planta nesta fase esta sem folhas. Isto pode explicar a maior produção de frutos das plantas submetidas a poda leve, que possuíam maior quantidade de reservas nas raízes no mês de maio, quando comparadas as plantas PD. 
As concentrações de carboidratos solúveis em ramos de pessegueiro submetidos a diferentes intensidades de poda verde, constam na tabela 6 .

Tabela 6. Concentrações de carboidratos solúveis em ramos de plantas (PL) e (PD), em pessegueiros ‘Flordaprince’, Piracicaba, 2005

\begin{tabular}{ccccccc}
\hline RAMOS & Out/03 & Dez/03 & Mar/04 & Mai/04 & Jul/04 & Set/04 \\
\hline PL* $^{*}$ 103,96A & $114,10 \mathrm{~A}$ & $95,31 \mathrm{~A}$ & $92,71 \mathrm{~A}$ & $81,74 \mathrm{~A}$ & $63,77 \mathrm{~A}$ \\
PD** & $103,96 \mathrm{~A}$ & 116,15A & 95,64A & 84,21A & $78,85 \mathrm{~A}$ & $62,56 \mathrm{~A}$
\end{tabular}

Médias seguidas por letras distintas em maiúsculo na coluna, diferem entre si pelo teste de Tukey ao nível de 5\% de probabilidade.

* PL = Poda verde de intensidade leve

** PD = Poda verde de intensidade drástica

Em relação aos carboidratos solúveis nos ramos, não houve diferença estatística de acordo com a época amostrada, para os dois tratamentos. Verifica-se que para os dois tratamentos a partir de dezembro, as reservas em ramos decresceram. Esses dados diferem dos observados por Flore \& Layne, (1996) que verificaram um máximo valor de carboidratos totais armazenados em ramos na metade do período de repouso vegetativo, o que corresponde a aproximadamente abril/maio para as nossas condições. Já, Borba, (2002) verificou as maiores concentrações de carboidratos solúveis em ramos no mês de julho, em plena frutificação. 


\section{CONCLUSÕES}

De acordo com os dados obtidos pelo presente trabalho, pode-se concluir que para a cultivar Flordaprince, nas condições de Piracicaba-SP, quanto mais intensa for a poda verde realizada em outubro:

- menor é a concentração de carboidratos solúveis nas raízes no período de dormência;

- maior é o crescimento de ramos após a sua execução;

- menor é a fixação de frutos no próximo ciclo;

- menores são os teores de sólidos solúveis nos frutos.

A intensidade da poda verde realizada nas mesmas condições, não interfere:

- na concentração de carboidratos solúveis em ramos;

- no florescimento efetivo, densidade de brotação e crescimento de ramos após a poda seca;

- no desenvolvimento, na massa, na coloração e na firmeza de frutos;

- na severidade de ferrugem em folhas de pessegueiro. 


\section{REFERÊNCIAS BIBLIOGRÁFICAS}

AGUSTI, M.; JUAN, M.; ARMELA, V. et al. Estímulo del desarrollo de los frutos de hueso. Valencia: Generalitat Valenciana, 1997. 78 p.

ALBUQUERQUE, A.S. Diversidade e parâmetros genéticos em pessegueiro (Prunus persica L. Batsch). Viçosa, 1997. 90 p. Dissertação (Mestrado) - Universidade Federal de Viçosa.

ANDERSON, W.H. Diseases of fruit crops. New York: McGraw-Hill, 1956. 501 p.

AZEVEDO, L.A.S. Manual de quantificação de doenças de plantas. São Paulo: O autor, 1997. $114 \mathrm{p}$.

BARBOSA, W. Desenvolvimento vegetativo e reprodutivo do pessegueiro em pomar compacto sob poda drástica. Piracicaba, 1989. 154 p. Tese (Doutorado) - Escola Superior de Agricultura “Luiz de Queiroz”, Universidade de São Paulo.

BARBOSA, W.; CAMPO-DALL'ORTO, F.A.; OJIMA, M. et al. Ecofisiologia do desenvolvimento vegetativo e reprodutivo do pessegueiro em região tropical. Campinas: Instituto Agronômico, 1990. 37p. (IAC. Documentos, 17) 
BARBOSA, W.; CAMPO-DALL'ORTO, F.A.; OJIMA, M. et al. O pessegueiro em pomar compacto: dez anos de produção de cultivares sob poda drástica bienal. Pesquisa Agropecuária Brasileira, v. 34, n.1, p.69-76, 1999.

BLEICHER, J.; TANAKA, H. Doenças do pessegueiro no Estado de Santa Catarina. 2. ed. Florianópolis: EMPASC, 1982. 53 p. (EMPASC. Boletim Técnico, 4).

BORBA, M.R.C. Teores de carboidratos em pessegueiros (Prunus persica (L.) Batsch) submetidos a diferentes tipos de poda. Piracicaba, 2002. 51 p. Dissertação (Mestrado) - Escola Superior de Agricultura “Luiz de Queiroz”, Universidade de São Paulo.

BOTREL, N.; CARVALHO, V.D. de; GONÇALVES, J.R.A. Estudo da evolução da maturação de dois cultivares de pêssegos (Prunus persica L. Batsch) destinados à industria. Ciência e Prática, v.17, n.4, p.363-369, 1993.

BOWEN, H.H. Breeding peaches for warm climates. HortScience, v.6, n.2, p.153-157, 1971.

BRASIL. Ministerio da Agricultura, Pecuária e Abastecimento. Anuário brasileiro de fruticultura 2002. Brasília, 2002. 176 p.

BRON, I.U. Alterações anatômicas e físico-quimicas associadas ao armazenamento refrigerado de pêssegos. Piracicaba, 2001. 66p. Dissertação (Mestrado) - Escola Superior de Agricultura “Luiz de Queiroz”, Universidade de São Paulo.

BROOKS, S.J.; MOORE, J.N.; MURPHY, J.B. Quantitative and qualitative changes in sugar content of peache genotypes (Prunus persica L. Batsch). Journal of the America Society for Horticultural Science, v.118, n.1, p.97-100, 1993. 
CALLESEN, O.; WAGENMAKERS, P.S. Effect of tree density, tree height and rectangularity on growth, flowering, and fruit production. Acta Horticulturae, n. 243, p.141-148, 1989.

CAMPO DALL'ORTO, F.A.; OJIMA, M.; BARBOSA, W. Fruticultura: queda de frutos imaturos. O Agronômico, v. 43, p. 2-3, 1991.

CAMPO DALL'ORTO, F.A.; OJIMA, M.; BARBOSA, W. et al. Cultivo de seleções de pessegueiros precoces no sistema de pomar compacto com poda drástica. Pesquisa Agropecuária Brasileira, v.19, n. 6, p. 719-727, 1984.

CHAPARRO, J.X.; WERNER, D.J.; WHENTTEN, R.W. et al. Inheritance, genetic interaction, and biochemical characterization of anthocyanin phenotypes in peach. The Journal of Heredity, v.86, p.32-38, 1995.

CITADINI, I.; RASEIRA, M.C.B.; HERTER, F.G. et al. Avaliação da necessidade de frio em pessegueiro. Revista Brasileira de Fruticultura, v. 24, n. 3, p.703-706, 2002.

DEJONG, T.M.; GOUDRIAAN, J. Modeling peach fruit growth and carbohydrate requirements: reevaluation of the double-sigmoid growth pattern. Journal of the American Society for Horticultural Science, v. 114, p. 800-804, 1989.

DEJONG, T.M.; DAY, K.R.; DOYLE, J.F. Evalution of training/pruning system for peach, plum and nectarine trees in Califórnia. Acta Horticulturae, n. 322, p. 99104, 1992.

DÍAZ, M.D.H. Regulacíon del reposo em duraznero bajo condiciones tropicales y subtropicales. Acta Horticulturae, n. 310, p.83-96, 1992. 
EMPRESA BRASILEIRA DE PESQUISA AGROPECUÁRIA. Sistema brasileiro de classificação de solos. Brasília, 1999. 412p.

FAO. Faostat: database results. http://www. fao.org 2003. (06 dez. 2004).

FAUST, M. Physiology of temperature zone fruit trees. New York: J. Wiley, 1989. 338p.

FUERTES, M.C.; HERNÁNDEZ, M.B.D. Poda de frutales y técnicas de propagación y plantación. Madrid: Mundi-Prensa, 1995. 267p.

GATO, E.M; HORTA, D.V. Poda de frutales $1^{\circ}$ la poda del ciruelo (Prunus salicina Lindl). Valencia: Generalitat Valenciana, Conselleria de Agricultura, Pesca y Alimentación, 1999. 103 p.

HADLICH, E.; MARODIN, G.A.B. Poda e condução do pessegueiro e da ameixeira. In: MONTEIRO, L.B.; MAY DE MIO, L.L.; SERRAT, B.M. et al. Fruteiras de caroço uma visão ecológica. Curitiba: UFPR, 2004. cap. 6, p.97-118

HEDRICK, U.P. The peaches of New York. New York: J.B. Lyon, 1916. 541 p.

HERTER, F.G.; SACHS, S.; FLORES, C.A. Condições edafo-climáticas para a Instalação do pomar. In: MEDEIROS, C.A.B.; RASEIRA, M.C.B. A Cultura do pessegueiro. Brasília: EMBRAPA, Serviço de Produção de Informação, 1998. cap. 2, p. 20-28.

HERTER, F.G.; GARDIN, J.P.P.; BACARIN, M. et al. Níveis de carboidratos em tecidos de pereira cv. Nijisseiki em duas épocas que antecedem o florescimento (compact disc). In: CONGRESSO BRASILEIRO DE FISIOLOGIA VEGETAL, 8., Ilhéus, 2001. Anais. Ilhéus: SBFV, 2001. 
HULME, A.C. The biochemistry of fruits and their products. New York: Academyc Press, 1970. v.1, 620 p.

KATAYAMA, T.; NAKAYAMA, T.O.M.; LEE, T.H. et al. Carotenoids transformations in ripening apricots and peaches. Journal of Food Science, v.36, p.804-806, 1971.

LAMMERTS, W.E. An evaluation of peach and nectarine variets in terms of winter chilling requirements and breeding possibilities Journal of the American Society for Horticultural Science, v.39, p.205-211, 1941.

LANG G.A.; EARLY, J.D.; MARTIN, G.C. et al. Endo-, para-, and ecodormancy: physiological terminology and classification for dormancy research. Hortscience, v.22, n.3, p. 371-377, 1987.

LEÓN, P.; SHEEN, J. Sugar and hormone conections. Trends in Plant Science, v.8, n.3, p.110-116, 2003.

LIVERANI, A.; CANGINI, A. Ethylene evolution and changes in carbohydrates and organic acid during maturation of two white and two yellow fleshed peach cultivars. Advances in Horticultural Science, v.5, n.2, p.59-63, 1991.

MARINI, P.M. Vegetative growth, yield and fruit quality of peachs influenced by dormant pruning, summer pruning, and summer topping. Journal of the American Society for Horticultural Science, v.110, n.2, p.223-230, 1985.

MARODIN, G.A.B.; FRANCISCONI, A.H.D.; GALLOIS, E.S.P. Efeito de produtos químicos na quebra de dormência e produção de Pereira (Pyrus communis, L.) cv Packham's Triumph. Revista Brasileira de Fruticultura, v.14, n.1, p.155-160, 1992. 
MARODIN, G.A.B.; SARTORI, A.S. Situação das frutas de caroço no Brasil e no mundo. In: SIMPÓSIO INTERNACIONAL DE FRUTAS DE CAROÇO: PÊSSEGOS, NECTARINAS E AMEIXAS, 1., Porto Alegre, 2000. Anais. Porto Alegre: UFRGS,DHS, 2000. p. 7-16.

MARODIN, G.A.B.; SARTORI, I.A.; GUERRA, D.S. Efeito da aplicação de cianamida hidrogenada e óleo mineral na quebra de dormência e produção do pessegueiro 'Flamecrest'. Revista Brasileira de Fruticultura, v. 24, n. 2, p.426-430, 2002.

MARQUAT, C.; VANDAMME, M.; GENDRAUD, M. et al. Dormancy in vegetative buds of peach: relation between carbohydrate absorption potentials and carbohydrate concentration in the bud during dormancy and its release. Scientia Horticulturae, v.79, p.151-162, 1999.

MARTINS, M.C. Quantificação dos parâmetros monocíclicos e controle químico da ferrugem do pessegueiro. Piracicaba, 1994. 68p. Dissertação (Mestrado) - Escola Superior de Agricultura “Luiz de Queiroz”, Universidade de São Paulo.

MARTINS, M.C. Caracterização morfo-fisiológica de Tranzchelia discolor, efeito da umidade na patogênese e controle da ferrugem no pessegueiro. Piracicaba, 1999. 81 p. Tese (Doutorado) - Escola Superior de Agricultura “Luiz de Queiroz”, Universidade de São Paulo.

MARTINS, M.C.; AMORIM, L. A ferrugem do pessegueiro. Summa Phytopathologica, v.22, p.193-199, 1996.

McGUIRE, R.G. Reporting of objective color measurementes. Hortscience, v.17, n.12, p.1254-1255, 1992. 
NIENOW, A.A. Comportamento morfológico, fenológico e produtivo de cultivares de pessegueiro (Prunus persica (L.) Batsch), submetidos a poda de renovação após a colheita na região de Jaboticabal/SP. Jaboticabal, 1997. 179 p. Tese (Doutorado). Faculdade de Ciências Agrárias, Universidade Estadual Paulista “Julio de Mesquita Filho”.

OGAWA, J.M.; ZHER, E.I.; BIRD, G.W. et al. Compendium of stone fruit diseases. St. Paul: APS Press, 1995. 98p.

OJIMA, M.; CAMPO-DALL'ORTO, F.A.; RIGITANO, O. et al. Melhoramento da nectarina em São Paulo. I. Cruzamento de 1970: seleção nas gerações F1 e F2. Bragantia, v.42, p.1-14, 1983.

OJIMA, M.; RIGITANO, O.; CAMPO-DALL’ORTO, F.A.; BARBOSA, W. et al. Fruticultura de clima temperado no Estado de São Paulo: diagnóstico da situação econômica e cultural e atividades de pesquisa no IAC. Campinas: Instituto Agronômico, 1984. 72 p. (IAC. Boletim Técnico, 89).

OLIEN, W. C. Analysis of orchard training system for production potencial na longterm stability. Acta Horticulturae, n. 322, p. 119-123, 1992.

PEREIRA, J.F.M.; RASEIRA, A.; FINARDI, N.L. Poda. In: EMPRESA BRASILEIRA DE PESQUISA AGROPECUÁRIA. Centro Nacional de Fruteiras de Clima Temperado. A cultura do pessegueiro. Pelotas, 1984. p.57-62. (EMBRAPA. CNPFT. Circular Técnica, 10).

PIZZA JÚNIOR, C.T.; BRAGA, F.G.A. A cultura do pessegueiro. São Paulo: Coordenadoria de Assistência Técnica e Integral, 1970. 144 p. (CATI. Boletim Técnico, 29). 
POWELL, L.E.; PRATTI, C. Growth promoting substances in the developing fruit peach (Prunus persica L. Batsch). Journal of Horticultural Science, v.41, p.331348, 1966.

PUTTI, L.G. Estudo das necessidades de frio e calor para a brotação de cultivares de macieira (Malus domestica, Borck.). Pelotas: Universidade Federal de Pelotas, 2001. $61 \mathrm{p}$.

QUICK, W.P.; SCHAFFER, A.A. Sucrose metabolism in sources and sinks. In: ZAMSKI, E.; SCHAFFER, A.A. Photoassimilate distribution in plants and crops: source-sink relationships. New York: Marcel Dekker, 1996. p.115-156.

RASEIRA, M.C.B.; NAKASU, B.H. Cultivares: descrição e recomendação In: MEDEIROS, C.A.B.; RASEIRA, M.C.B. A cultura do pessegueiro. Brasília: EMBRAPA, Serviço de Produção de Informação, 1998. cap. 3, p. 29-99.

RASEIRA, A.; PEREIRA, J.F.M. Poda do pessegueiro. Hortisul, v.1, n.1, p.17-19, 1989.

RASEIRA, A.; PEREIRA, J.F.M.; MEDEIROS, A.R.M. et al. Instalação e manejo do pomar. In: MEDEIROS, C.A.B.; RASEIRA, M.C.B. A cultura do pessegueiro. Brasília: EMBRAPA, Serviço de Produção de Informação, 1998. cap. 5, p. 130-160.

SACHS, S.; HERTER, F.G.; NAKASU, B.H. et al, A cultura do pessegueiro. Pelotas: Embrapa,CNPFT, 1984. 156 p. (Embrapa. CNPFT. Circular Técnica, 10).

SACHS, S.; CAMPOS, A.D. O pessegueiro. In: MEDEIROS, C.A.B.; RASEIRA, M.C.B. A cultura do pessegueiro. Brasília: EMBRAPA, Serviço de Produção de Informação, 1998. cap. 1, p. 13-19 
SALISBURY, F. B.; ROSS C. W. Plant physiology. Belmont: Wadsworth Pub., 1992. $682 \mathrm{p}$.

SAMISH, R.M. Dormancy in wood plants. Annual Review of Plant Physiology, v.5, p.183-204, 1954.

SCARPARE FILHO, J.A.; KLUGE, R.A.; JACOMINO, A.P. et al. Comparação entre dois sistemas de condução de pessegueiros em pomar compacto. Revista Brasileira de Fruticultura, v. 21, n. 1, p. 92-94, 1999.

SIMÃO, S. Tratado de fruticultura. Piracicaba: FEALQ, 1998. 760 p.

STEINBERG, E. Pêssego e nectarina. São Paulo: Livraria Nobel, 1989. 64 p.

SUTTON. J.C.; GILLESPIE, T.J.; HOLDEBRAND, P.D. Monitoring weather factors Plant Disease, v.68, n.1, p.78-84, 1984.

TAIZ, L.; ZEIGER, E. Plant physiology. New York: The Benjamin Cummings, 2002. $56 \mathrm{p}$.

TONUTTI, P.; BONGUI, C.; RAMINA, A. Fruit firmness and ethylene biosynthesis in three cultivars of peach genotypes (Prunus persica L. Batsch) Journal of Horticultural Science, v.71, n.1, p.141-147, 1996.

WILLIAMS, M.W.; MARTIN, G.C.; STAHLY, E.A. The movement and fate of sorbitol $-{ }^{14} \mathrm{C}$ in the apple tree and fruit. Proceedings of the American Society for Horticultural Science, v.90, p.20-24, 1967. 
YARNELL, S.H.; COLLEGE, A.; COLLEGE, M. Texas studies on the cold requirements of peaches. Journal of the American Society for Horticultural Science, v.37, p.349-352, 1939.

ZANCHIN A.; BONGUI, C.; CASADORO, G. et al. Cell enlargement and cell separation during peach fruit development. International Journal of Plant Sciences, v.115, n.1, p.49-56, 1994.

ZENTMYER, G.A.; BALD, J.G. Managemente of the environment. In: HORSFALL, J.G.; COWLING, E.B. Plant disease: an advanced treatise. New York: Academic Press, 1977. cap.7, p.121-144. 
APÊNDICES 
Apêndice 1. Dados climatológicos de Piracicaba, período de 2003/2004.

\begin{tabular}{|c|c|c|c|c|c|c|c|c|c|}
\hline \multicolumn{5}{|c|}{ Ano de 2003} & \multicolumn{5}{|c|}{ Ano de 2004} \\
\hline Mês & $\begin{array}{l}\text { Precipi- } \\
\text { tação } \\
(\mathrm{mm})\end{array}$ & $\begin{array}{c}\text { Umidade } \\
\text { Relativa } \\
\text { (\%) }\end{array}$ & $\begin{array}{c}\mathrm{T} \\
\text { Média } \\
{ }^{\circ} \mathrm{C}\end{array}$ & $\begin{array}{l}\text { Evapo- } \\
\text { ração } \\
(\mathrm{mm})\end{array}$ & Mês & $\begin{array}{l}\text { Precipi- } \\
\text { tação } \\
\text { (mm) }\end{array}$ & $\begin{array}{c}\text { Umidade } \\
\text { Relativa } \\
\text { (\%) }\end{array}$ & $\begin{array}{c}\mathrm{T} \\
\text { Média } \\
{ }^{\circ} \mathrm{C}\end{array}$ & $\begin{array}{l}\text { Evapo- } \\
\text { ração } \\
(\mathrm{mm})\end{array}$ \\
\hline Jan & 302,4 & 92,16 & 24,89 & 5,39 & Jan & 196,4 & 83,19 & 23,1 & 4,95 \\
\hline Fev & 58,6 & 82,64 & 26,48 & 5,82 & Fev & 194,0 & 86,24 & 23,98 & 5,93 \\
\hline Mar & 180,9 & 86,23 & 24,32 & 4,78 & Mar & 79,1 & 83,03 & 23,44 & 5,65 \\
\hline Abr & 55,2 & 83,23 & 22,57 & 3,96 & Abr & 92,3 & 82,93 & 23,02 & 4,14 \\
\hline Mai & 54,7 & 79,61 & 18,78 & 3,20 & Mai & 105,9 & 89,19 & 18,55 & 2,66 \\
\hline Jun & 9,2 & 79,67 & 20,08 & 3,12 & Jun & 49,7 & 84,70 & 17,62 & 2,41 \\
\hline Jul & 16,4 & 72,10 & 18,89 & 3,60 & Jul & 78,4 & 82,81 & 17,43 & 2,65 \\
\hline Ago & 17,8 & 72,61 & 18,51 & 3,78 & Ago & 0,0 & 64,74 & 18,57 & 4,30 \\
\hline Set & 12,1 & 70,30 & 21,40 & 5,36 & Set & 7,1 & 61,17 & 23,67 & 5,89 \\
\hline Out & 89,2 & 74,39 & 23,13 & 5,78 & Out & 156,9 & 80,68 & 24,74 & 4,57 \\
\hline Nov & 176,5 & 81,1 & 24,71 & 6,07 & Nov & 168,0 & 78,30 & 23,62 & 5,57 \\
\hline Dez & 166,1 & 85,71 & 26,41 & 5,83 & Dez & 139,9 & 83,94 & 24,93 & 6,06 \\
\hline
\end{tabular}

Fonte: LCE - ESALQ/USP 
Apêndice 2. Análise química de solo em pomar experimental de pessegueiro 'Flordaprince' nas profundidades de 0-20 cm e 20-40 cm em Piracicaba.

\begin{tabular}{|c|c|c|c|c|c|c|c|c|c|c|}
\hline & $\mathrm{pH}$ & $\mathrm{MO}$ & $\mathrm{P}$ & $\mathrm{K}$ & $\mathrm{Ca}$ & $\mathrm{Mg}$ & $\mathrm{H}+\mathrm{Al}$ & SB & $\mathrm{T}$ & V\% \\
\hline & $\mathrm{CaCl}_{2}$ & g. $\mathrm{dm}^{-3}$ & $\mathrm{mg} \cdot \mathrm{dm}^{-3}$ & \multicolumn{7}{|c|}{ mmolc. $\mathrm{dm}^{-3}$} \\
\hline $0-20$ & 6,0 & 8 & 8 & 5,3 & 50 & 38 & 20 & 93,3 & 73,7 & 82 \\
\hline $20-40$ & 5,3 & 3 & 3 & 2,7 & 25 & 21 & 25 & 48,7 & 113,3 & 66 \\
\hline
\end{tabular}


Apêndice 3. Teores de nutrientes em folhas de pessegueiro 'Flordaprince' submetidos a poda leve e poda drástica em Piracicaba.

\begin{tabular}{cccccc}
\hline \multicolumn{3}{c}{ Tratamento (1) - PL - Médias } & \multicolumn{3}{c}{ Tratamento (2) - PD - Médias } \\
Nutriente & $\%$ & Diagnose & NUTRIENTE & $\%$ & Diagnose \\
\hline $\mathrm{N}$ & 3,2 & Normal & $\mathrm{N}$ & 3,5 & Normal \\
$\mathrm{P}$ & 0,19 & Normal & $\mathrm{P}$ & 0,19 & Normal \\
$\mathrm{K}$ & 2,83 & Excesso & $\mathrm{K}$ & 3,02 & Excesso \\
$\mathrm{Ca}$ & 1,83 & Normal & $\mathrm{Ca}$ & 1,62 & Abaixo do normal \\
$\mathrm{Mg}$ & 0,31 & Abaixo do normal & $\mathrm{Mg}$ & 0,36 & Abaixo do normal \\
$\mathrm{S}$ & 0,14 & & $\mathrm{~S}$ & 0,11 & \\
& $\mathrm{mg} / \mathrm{kg}$ & & & $\mathrm{mg} / \mathrm{kg}$ & \\
$\mathrm{B}$ & 35,7 & Normal & $\mathrm{B}$ & 30,6 & Abaixo do normal \\
$\mathrm{Cu}$ & 10,3 & Normal & $\mathrm{Cu}$ & 9,1 & Normal \\
$\mathrm{Fe}$ & 318,4 & Acima do normal & $\mathrm{Fe}$ & 349,7 & Excesso \\
$\mathrm{Mn}$ & 58,9 & Normal & $\mathrm{Mn}$ & 58,0 & Normal \\
\hline
\end{tabular}

